\title{
Sovereign Debt Renegotiation and Credit Default Swaps
}

\author{
Juliana Salomao* \\ University of Minnesota
}

December 17, 2014

\begin{abstract}
A credit default swap (CDS) contract provides insurance against default. After a country defaults, the country and its lenders usually negotiate over the share of the defaulted debt to be repaid. This paper incorporates CDS contracts into a sovereign default model and demonstrates that the existence of a CDS market results in lower default probability, higher debt levels, and lower financing costs for the country. Since the CDS payout is not automatically triggered by losses from renegotiations, the lender needs to be compensated for lower expected insurance payments. This leads to higher debt repayment in renegotiation, decreasing the benefits of defaulting, and hence allowing the country to borrow more at lower rates. Uncertainty over the insurance payout when the debt is renegotiated explains why in the data, as the output declines, the CDS spread becomes lower than the bond spread. Furthermore, this pricing dynamic during a debt crisis can be used to infer market perceptions of the probability of the CDS paying out after a renegotiation. The model is calibrated to Greek data and shows that increasing CDS levels from 0 to $5 \%$ of debt lowers the unconditional default probability from $2.6 \%$ to $2.0 \%$ per year with no impact on debt level. Further increasing the CDS to $40 \%$ of debt increases the equilibrium debt level by $15 \%$, but also increases the probability of default to $3.1 \%$.
\end{abstract}

Keywords: Sovereign default, credit default swaps, negative basis

JEL Codes: F30, F34, F41

*I am deeply indebted to Martin Schneider, Manuel Amador, Pablo Kurlat and Monika Piazzesi for their support and guidance through this journey. I also thank seminar participants at the Stanford Macroeconomics Lunch and Finance Reading Group, Office of Financial Reseach, Federal Reserve Board, Federal Reserve Bank of St.Louis, University of Notre Dame, UCSD, University of Maryland, NYU Stern, University of Toronto, University of Chicago Booth, University of Minnesota Carlson, USC Marshall, PUC-Rio, Federal Reserve Bank of Philadelphia, the World Bank, Federal Reserve Bank of Minneapolis. Support from Kohlhagen Fellowship Fund and the Haley-Shaw Fellowship Fund of the Stanford Institute for Economic Policy Research (SIEPR) is gratefully acknowledged. Correspondence: Department of Finance, University of Minnesota. 321 - 19th Avenue South Minneapolis, MN 55455. Email: jsalomao@umn.edu 


\section{Introduction}

A credit default swap (CDS) contract provides insurance against the borrower's failure to repay debt obligations. The CDS market has experienced striking growth in recent years, expanding from $\$ 6$ trillion in 2004 to $\$ 26$ trillion 2012. The CDS contract is designed in such a way that its payout is not automatically activated by the debt holders' losses during debt renegotiation (not full default), which is the usual procedure when a country defaults. The recent European debt crisis is the first sovereign crisis in which investors have been able to buy insurance against a country's decision to default, and has highlighted this feature of the contract. In March 2012, Greece renegotiated its privately held debt, and there was high uncertainty about whether the CDS payment would be triggered. This paper incorporates a CDS market with payout uncertainty into a standard sovereign endogenous default model to understand the effects of this market on the default probabilities, debt levels, prices of the bond and the underlying CDS.

First, the model shows that the existence of a CDS contract increases the lenders' bargaining power during debt renegotiation and the share of debt repaid by the country in renegotiation for all debt levels. In the model, CDS-insured lenders always receive an insurance payout in case of full default (zero repayment), but face uncertainty regarding payments in the event of a debt renegotiation agreement. Hence, lenders are less willing to accept the renegotiated terms. With a CDS market, the borrower must compensate lenders for lower expected insurance payments upon accepting an agreement for debt renegotiation. The country compensates its lenders by increasing the debt share repaid. Because the country has to pay more in default, this option becomes less attractive. Therefore, the country can credibly commit not to default in more states of the world. This leads to higher equilibrium debt levels and lower debt financing costs. Also, the uncertainty over insurance payouts when the bond defaults explains why as the output declines, the CDS spread becomes lower than the bond spread.

Second, to assess the quantitative effects of the CDS market, the model is calibrated to Greek data. The pricing dynamics of the CDS and bonds during the Greek crisis is used to infer the market perception of the probability of insurance paying out when debt holders incur losses. Using this probability estimation and assuming that $5 \%$ of the outstanding debt is covered by CDS contracts, the model quantitatively matches the behavior of CDS and bond prices during the crisis. ${ }^{1}$ Simulation results reveal that increasing the CDS-to-

\footnotetext{
${ }^{1}$ Most countries have between 0 and $10 \%$ of their debt insured with CDS, see Figure $2 \mathrm{~A}$ in the appendix. The average level of CDS-Debt coverage between 2008 and 2012 for Greece is 2.5\%. However this excludes Greece's participation on CDS indexes.
} 
debt ratio from 0 to $5 \%$ lowers the unconditional probability that a country like Greece will default from $2.6 \%$ to $2.0 \%$ per year, with negligible effects on the average debt-to-GDP ratio. Increasing the CDS coverage to $40 \%$ of the debt results in a $15 \%$ higher equilibrium debt-to-GDP ratio but also a higher probability of default of $3.11 \%$ per year.

The key motivation of this paper is the structure of CDS contracts, specifically the uncertainty over classifying the defaults that trigger insurance payments. In the absence of an international bankruptcy law, the defaulting country and its lenders usually renegotiate over the reduction of defaulted debt. Unlike previous default episodes, such as the Argentinian debt crisis of 2002, the CDS market adds a settlement between the CDS buyer and the seller after the debt renegotiation is complete. After an agreement is reached between the country and its lenders, the holders of the CDS file a claim with the International Swaps and Derivative Association (ISDA) to trigger the insurance payment. As became evident during the Greek debt default, this trigger is not automatically activated by the debt holders' loss during renegotiation. ${ }^{2}$ The ISDA's Determination Committee votes on whether the default classifies as a credit event triggering the CDS payout. ${ }^{3}$ Since the CDS payout is at the Determination Committee's discretion, the lenders do not know if their insurance will cover losses when they accept the repayment agreement from the country.

The possibility that a CDS may not pay out results in a discrepancy between the price of the CDS and a bond. The difference between the cost of insurance (price of the CDS) and the premium paid to the lender for holding the default risk (risky bond spread) is called the CDS-Bond basis. For countries that are not going through a debt crisis, this basis is close to zero. However, when borrowers are going through debt crises, the cost of insuring the country's default risk is lower than the premium paid to the lenders for holding the same risk, making this basis negative. Figure 1 shows output (GDP) and the CDS-Bond basis for Greece from 2008Q1 to 2011Q3. ${ }^{4}$ The plot reveals that the basis is highly negative for most of the period - and also highly correlated with output. The lower the output, the higher the probability of default and the more negative the basis. This evidence is consistent with the lenders' expectations that the CDS may not pay out even if the bond is not fully repaid.

The proposed model is a dynamic endogenous default model with post-default bargaining and long-term CDS contracts. The model environment consists of three agents: a sovereign country, a lender, and an insurance provider. The latter two are risk-neutral. The sovereign

\footnotetext{
${ }^{2}$ For corporate non-repayment events with CDS trigger uncertainty, see Bolton and Oehmek (2011).

${ }^{3}$ As discussed in Hatchondo, Martinez and Sapriza(2014) most of the current renegotiations happened without any payments being missed. This gives space for the renegotiation being considered voluntary, which may not trigger the CDS.

${ }^{4}$ See Figure 1A in the appendix for similar plots for Portugal, Ireland, Italy, Spain and France. For all these countries, excluding France, the basis becomes negative as output falls.
} 
Figure 1: GDP and CDS-Bond Basis for Greece

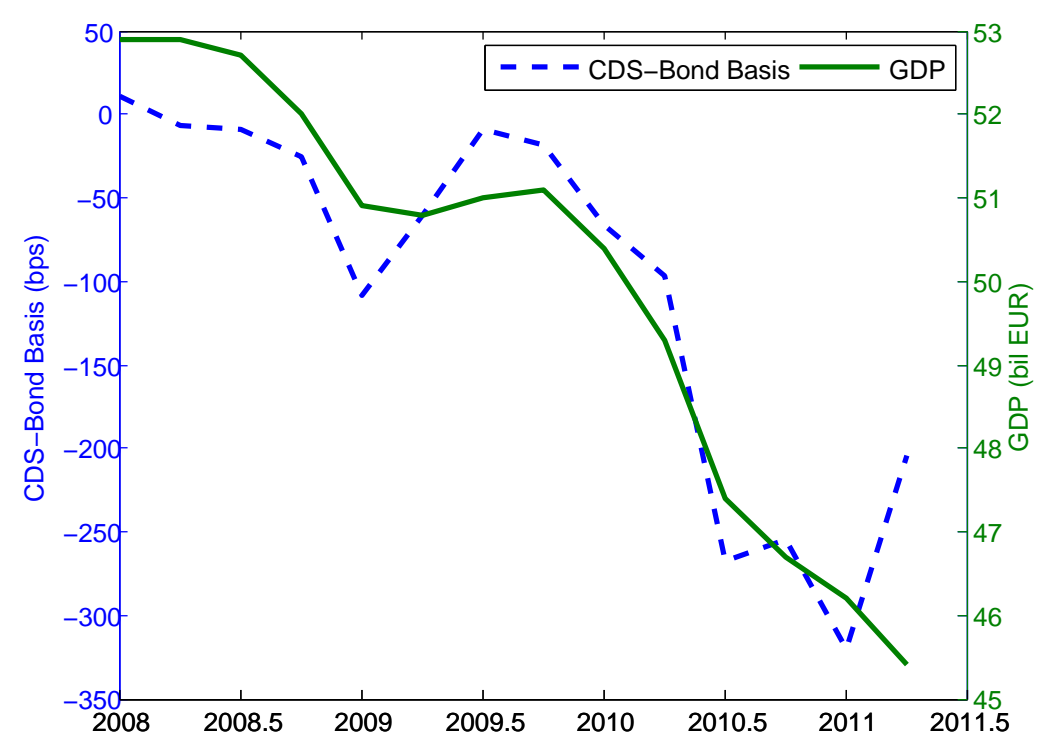

Note: This figure plots the CDS-Bond basis for Greece between 2008 and 2011.25 in the left axis. This basis is the difference between the 5 year maturity CDS running spread and the 5 year maturity bond spread between the Greek bond and the German bond. Both contracts are USD (data from Datastream). On the right axis is plotted Greece's real annual GDP in bil of euros (seasonally adjusted).

country is risk-averse and earns a stochastic endowment. The sovereign's objective is to maximize the utility of a representative citizen by smoothing consumption through the issuance of long-duration bonds. In each period, the country must decide whether to repay the debt. A novel feature of the model is that lenders can purchase CDS contracts from the insurance provider that will pay the face value of the bond in case of a credit event.

If the country decides not to repay its debt, the country and its lenders will enter debt renegotiation over the share of the debt that is not repaid (the haircut on the debt). This renegotiation is modeled as a Nash bargaining problem. If there is an agreement over the share to be repaid, the country: (a) repays the agreed amount by issuing new long term bonds; (b) incurs output costs; and (c) is excluded from the market for a finite number of periods. Also, lenders receive the agreed amount from the country and the full face value of the insured debt if a credit event is declared. However, after the agreement, there is a possibility that the default will not be declared a credit event by the Determinations Committee, in which case the CDS contracts will not pay out. If no agreement is reached: (a) the country repays nothing to the lender and can never re-enter the credit market; and 
(b) the lenders' CDS triggers with certainty. ${ }^{5}$

The presence of CDS changes the bargaining game. When there is an agreement, the lenders are subject to expected losses. By approving the deal, they also accept the uncertainty of the CDS payout versus certain repayment if they reject the agreement. Due to these expected losses, the lender becomes a "tougher" negotiator, demanding a smaller haircut (higher repayment) as compensation for the expected loss. In equilibrium, the country chooses to default less frequently, making financing cheaper and debt levels higher.

One important feature of the model is the Determination Committee's rule for declaring a credit event, that is, the probability function of the CDS triggering after an agreement. The probability function of triggering is modeled as a function of the repayment share after default: The higher the repayment share post-default, the less likely the CDS will trigger. Intuitively, if the country and its lenders agree to a small haircut (the majority of the debt is repaid), it is likely that the committee will consider this a voluntary restructuring since the bond holders incurred a small loss. In this case, the CDS will have a low probability of triggering. If the repayment is closer to zero, it is more likely the committee will classify the default as a credit event.

The effect of the CDS depends on the level of insured debt and the probability of a credit event being declared for a given haircut. The level of insured debt in the market is set as an exogenous parameter. The model is calibrated on data from Greece and solved for multiple levels of CDS debt coverage and trigger probability functions. The dynamics of the CDSBond basis observed during the Greek crisis are used to infer the triggering function (i.e., the market perception of the decision rule of the Determination Committee in categorizing a default event as a credit event). Using this triggering function and assuming that 5\% of the outstanding debt is insured, the model quantitatively matches the behavior of the basis during the crisis. Simulation results indicate that at the current CDS-to-debt ratios of $5-10 \%$, the unconditional probability of default and the spread are both lower than in a "no CDS" benchmark. The calibration for Greece reveals that increasing the CDS-to-debt ratio from 0 to $5 \%$ lowers the frequency of default from $2.6 \%$ to $2.0 \%$ per year, with negligible effects on the average debt-to-GDP ratio. If the level of insured debt is increased to $40 \%$, the equilibrium debt-to-GDP ratio increases by $15 \%$ and the probability of default increases to $3.11 \%$.

The CDS at current levels (5-10\%) is welfare-improving because it allows countries to better smooth consumption by paying lower spreads. The welfare levels of the lender and insurer are unchanged, so the introduction of the CDS at those levels is a Pareto improvement.

\footnotetext{
${ }^{5}$ See Figure $3 \mathrm{~A}$ in the appendix for a timeline post-default.
} 
On the other hand, if the CDS level is too high (40\%) and the probability of triggering is very low, the welfare of the country decreases. This occurs because the lenders are exceedingly tough in renegotiation and the country must repay a large amount when defaulting, which coincides with states when output is low.

\section{Related Literature}

This paper builds primarily on three strands of literature: (1) endogenous sovereign default models; (2) the corporate finance empty-creditor problem; and (3) empirical evidence on price discrepancies between the CDS and bonds. This paper introduces a CDS market to the sovereign default problem and demonstrates how the existence of this market alters borrower and lender renegotiation in default. The effect of the CDS on the renegotiation problem has consequences for debt levels, spreads, and probabilities of default in equilibrium. Also, this paper reveals that the contractual uncertainty over what classifies as an insurance payment-triggering default is crucial for the CDS market's effect on renegotiation. Finally, by incorporating the contractual peculiarities of the CDS, the model is able to explain and generate the price discrepancies documented in the empirical literature.

The original model of defaultable debt developed in Eaton \& Gersovitz (1981) gave birth to a vast quantitative literature that focuses on explaining the unique characteristics of emerging-market business cycles (Neumeyer and Perri [2005], Aguiar and Gopinath [2006], and Arellano [2008]). This part of the literature assumes that debt is issued as one-period bonds with no repayment after default, which leads to some difficulties in matching the calibrated models to the default risk and debt levels in the studied economies.Yue (2010) adds to the standard a Nash bargaining game post-default which determines endogenous debt recovery rates. Her results show that adding this feature leads to higher default probabilities and greater interest rate volatility, improving the model's fit of the data. In their recent work, Chatterjee and Eyigungor (2012) and Hatchondo and Martinez (2009) demonstrate that models with long-term defaultable bonds provide a better fit to emerging-market data by matching the volatility and average of the country spread and debt levels. By adding a CDS market, my model allows analysis of the effects of this new market on sovereign borrowing, which has not yet been examined in the literature.

Corporate finance literature took the lead in analyzing the effect of CDS contracts on the strategic behavior of lenders and borrowers. Hu and Black (2007) argue that the CDS contract transfers the default risk from the creditors to the protection sellers, resulting in the so-called empty creditor problem. They suggest that creditors holding CDS have lower incentives for helping a debtor avoid default by rolling over debt, granting new financing or agreeing to voluntary restructuring. Bolton and Oehmke (2011) analyze the empty creditor 
problem in a three-period model, in which a firm with limited commitment issues debt in the first period to finance a two-period project with stochastic cash flow. The firm's debt renegotiation at the interim date after the cash flow of period two is realized, plays a central role in the model. In the paper, the debt renegotiation game is modified as a result of lenders holding CDS contracts. Specifically, a lender holding CDS protection has a better outside option in an out-of-court renegotiation since the CDS pays out when the renegotiation fails and the firm goes into default. This outside option allows the lender to extract more in renegotiation from the firm. In this paper, I demonstrate that not only the outside option, but also the lenders' lower expected insurance payments, are critical for the CDS effects on borrowing. In addition, the dynamic model offers quantitative answers regarding the effects of this insurance market.

Fontana and Scheicher (2010) analyze weekly observations from January 2006 to June 2010 on the CDS spreads and bond yields of ten Euro-area countries. They document a positive basis (CDS spread>Bond spread) for most of the countries during that period. They propose as one possible explanation the "flight to quality" effect that lowers government bond spreads in periods of market distress. They also reported a negative basis for Portugal, Ireland, and Greece starting in 2009 but are unable to explain it. Bai and Collin-Duffresne (2013) investigate the cross-sectional variation in the CDS-Bond basis for investment-grade and high-yield corporate bonds. They test several explanations for the violation of the arbitrage relation between cash bonds and CDS contracts, which state that the basis should be zero. They find that during the 2007-2009 financial crisis, the negative basis is consistent with "limits to arbitrage" theories, since deviations were larger for bonds with higher frictions, as measured by trading liquidity, funding cost, and counterpart risk. However, most of these standard risk factors lost explanatory power after the crisis, even though the CDS-Bond basis remained negative on average and volatile - a fact that they found puzzling. In this paper, I show that since the CDS is an imperfect form of insurance, it is not surprising to find a negative basis during debt crises.

The remainder of this paper is organized as follows. The next section discusses details of the CDS market and its regulation. In Section 3, a two-period model is presented to explain the intuition behind the effects of the CDS on debt levels and spreads. Section 4 presents the model environment, preferences, and market arrangement. Section 5 describes the dynamic sovereign borrower and lender's problem and defines a recursive equilibrium. Section 6 presents the model calibration and quantitative analysis. Finally, Section 7 offers concluding remarks. 


\section{The Credit Default Swaps Market}

The credit default swap (CDS) is an insurance contract that protects creditors against losses incurred when a debtor defaults on its debt obligations. In this contract, the "CDS buyer" pays a periodic fee (CDS spread) to the "CDS seller" in exchange for a pre-stipulated payment from the seller if a "credit event" occurs on a reference credit instrument within a predetermined time period. The stipulated amount contracted is typically the face-value of the bond and the typical maturity of a CDS is 5 years. The reference credit instrument may be a corporate or a sovereign entity.

The CDS market remains to a large extent unregulated. ${ }^{6}$ However, guidance on the legal and institutional details of CDS contracts is given by the International Swaps and Derivatives Association (ISDA). The association has played a significant role in the CDS market by creating a standardized contract (the ISDA Master Agreement) for entering into derivatives transactions. The contract was created in 1992, updated in 2002 and in 2009 the ISDA introduced further compulsory modifications known as the "Big Bang Protocol" for the US and "Small Bang Protocol" for Europe. ${ }^{7}$

The modifications introduced by the two bangs were intended to improve the efficiency of the CDS market by further standardizing some features of the contract. The main changes that were introduced were: (1) forming Determination Committees (DCs) to determine whether a credit event had occurred as well as establishing the terms of the auction to determine the CDS payout amount; (2) hardwiring the auction mechanism for CDS following a credit event; and (3) standardizing all trade CDS contracts as upfront payment contracts with fixed coupons. ${ }^{8}$

The ISDA has five DCs, each of which has jurisdiction over a specific region of the world: (a) the Americas, (b) Asia (excluding Japan), (c) Australia/New Zealand, (d) EMEA (Europe, Middle East and Africa), and (e) Japan. Each committee is composed of: eight global dealers, two regional dealers for each region, five buy-side members, two non-voting dealers, one non-voting buy-side member, and the ISDA as a non-voting secretary. ${ }^{9}$ In total,

\footnotetext{
${ }^{6}$ A provision in the Commodity Futures Modernization Act exempts CDS from regulation by the Commodity Futures Trading Commission (CFTC)

${ }^{7}$ In August 2014, ISDA also made some changes regarding some definitions of credit events. The major change was the introduction of a new Credit Event, Government Intervention, with respect to non-U.S. financial Reference Entities. The necessity for this new Credit Event became obvious in early 2013 when the Dutch government nationalized SNS Bank and expropriated all of its subordinated bonds. Another important change was the inclusion of the renegotiated bond for physical settlement.

${ }^{8}$ Previously, contracts could also be traded with a variable spread and no upfront payment.

${ }^{9}$ To become a dealer: (1) participating bidder in auctions, (2) adhere to the Big Bang protocol. To become a buy-side member the institution (1) must have at least $\$ 1$ billion in assets under management, (2)
} 
there are 15 voting members and 3 non-voting members plus the secretary. The buy-side on the DC must include at least one hedge fund and one traditional asset manager at all times. No institution can serve a second term until all eligible institutions have served.

To start the voting process, any ISDA member may request a DC to be convened to address a question, usually concerning the occurrence of a credit event that would trigger the CDS. One member of the committee must agree to consider the question. If an $80 \%$ super majority (12 out of the 15 members) is not achieved on any question, the issue automatically goes before an external review panel.

The EMEA committee met twice in 2012 to vote on whether the Greek debt restructuring constituted a credit event. First, on March 1, the committee met to vote on two questions on whether a restructuring credit event had happened that would trigger the CDS payout. The first questioned if the fact that holders of Greek law bonds had been subordinated to the ECB constituted a restructuring credit event. ${ }^{10}$ The second questioned if the agreement between the Hellenic Republic and the private holders of Greek debt constituted a restructuring credit event. ${ }^{11}$ To both questions the committee unanimously voted no, defending that the restructuring was a voluntary renegotiation, which does not trigger the CDS. After the second meeting on March 9, it was announced that $85.8 \%$ of private holders of Greek government bonds regulated by Greek law, had agreed to the debt restructuring deal. As this number was above the $66.7 \%$ threshold, it enabled the Greek government to activate a collective action clause (CAC), so that the remaining $14.2 \%$ were also forced to agree. The committee ruled that after the CACs were invoked by Greece to force all holders to accept the exchange offer for existing Greek debt constituted a credit event.

When a credit event is determined, an auction is held to facilitate settlement of a large number of contracts at once, at a fixed cash settlement price. During the auction process participating dealers submit prices at which they would buy and sell the reference entity's debt obligations, as well as requests for physical settlement (where the bond is exchanged) against par. A second stage Dutch auction is held following the publication of the initial midpoint of the dealer markets. The final clearing point of this auction sets the price for cash settlement of all CDS contracts and all physical settlement requests are actually settled.

The ISDA has also been working on reducing the counterparty risk in the CDS market, another key area. During the past years, counterparty risk has emerged as one of the have single name CDS trade exposure at least $\$ 1$ billion and be approved by $1 / 3$ of the then current buy-side pool.

${ }^{10}$ The bonds owned by the ECB became senior (being immune to haircut) to the bonds owned by everybody else.

${ }^{11}$ In a marathon meeting in Brussels private holders of governmental bonds accepted a slightly bigger haircut of $53.5 \%$. 
important risk factors in the derivatives market. One way to mitigate counterparty risk is through collateralizing the exposure. This practice has become the industry standard. According to the ISDA Margin Surveys in 2012, 83\% of all CDS transactions were subjected to collateral agreements, where most of the collateral posted was cash (79.5\%). ${ }^{12}$ Arora, Gandhi and Longstaff (2012) measure empirically the magnitude of counterparty risk in the CDS market. They analyze CDS transaction prices and quotes by 14 different CDS dealers selling protection on the same underlying firm. The authors find that the magnitude is very small and consistent with a highly collateralized market. Their results indicate that an increase in the dealer's credit spread of 645 basis points only translates into a one basis-point decline on average in the dealer's spread for selling credit protection.

\section{Two Period Model}

This section illustrates how CDS contracts affect the level and price of debt in a simplified, two-period version of the model. The country (borrower) has a preference for smooth consumption over the two periods. Its income is low today and stochastic tomorrow. For concreteness, let's assume that income is zero today and tomorrow can take three values, $y_{L}<y_{M}<y_{H}$ with probabilities $\left[p_{L}, p_{M}, 1-p_{L}-p_{M}\right]$.

The borrower can issue non-contingent bonds to shift resources from the future into the present. The price $q(b)$ of a bond depends on the number $b$ of bonds issued. The country borrows an amount $q(b) b$ today and repays $b$ tomorrow. Once $y_{i}$ is realized, the borrower has the option of defaulting on the debt $(b)$, after which the borrower and lender enter a one-shot Nash bargaining game that determines the share $\alpha \epsilon[0,1]$ of each dollar of the debt the borrower will repay the lender. If the country defaults and reaches an agreement with the lender $(\alpha>0)$, the country loses a share $c_{a}$ of its output tomorrow. In the case of default without an agreement $(\alpha=0)$, the country loses a share $c_{n a}$ of tomorrow's output $\left(c_{n a}>c_{a}\right)$. The top tree in Figure 2 shows the borrower's payoff structure.

The lender can enter a trade with a third party (CDS seller) that provides insurance in case the country decides to default. The CDS contract specifies that today, the CDS buyer pays $q_{c d s}(b)$ to the seller in exchange for the payment, tomorrow, of the amount not repaid by the borrower $(1-\alpha)$ on each dollar of covered debt. This repayment only happens if the borrower chooses to default and the regulators of the CDS market rule that the CDS triggers, paying out $(1-\alpha)$. The lender purchases a share $d \epsilon[0,1)$ of coverage through CDS contracts. Full coverage is not available, so $d<1$.

\footnotetext{
${ }^{12}$ The numbers for previous years are of similar magnitude.
} 
The CDS contract states that if the borrower and the lender reach an agreement on the repayment share $(\alpha>0)$, the CDS will have a probability $\left(p^{\text {trigger }}\right)$ of paying out (i.e. triggering) that increases with the haircut $(1-\alpha)$ - i.e. share of the debt that the country will not repay. However, if there is no agreement the CDS will pay out with certainty and the country will not repay any of the debt to the lender $(\alpha=0)$. The bottom tree in Figure 2 displays the bond payoff for the lender.

Ownership of CDS securities changes the bargaining game for the lender. With this security, the lender is subject to expected losses by agreeing to the repayment share, since by agreeing to the deal he also accepts the uncertainty of the CDS payout versus the certain CDS repayment if he rejects the agreement. Due to this uncertainty, the lender becomes a "tougher" negotiator, demanding a smaller haircut (higher repayment) as compensation for the expected loss.

Figure 2: Borrower and Lender Payoffs
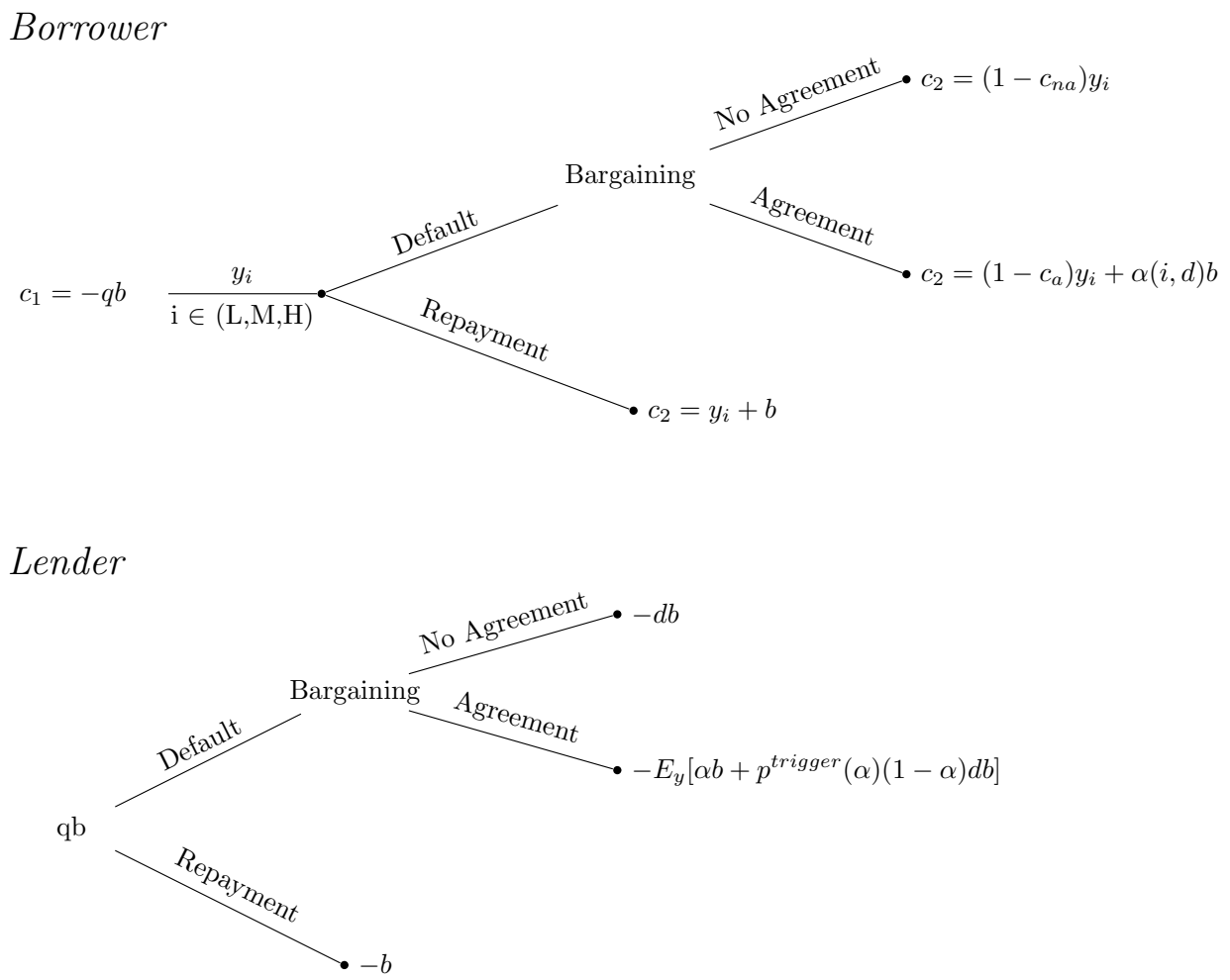

Note: The top tree reports the borrower's payoff structure from borrowing b in period 1 and choosing to default or repay. The bottom tree has the lender's payoff from lending $b$ and bargaining post-default with the country. 


\section{Bargaining Problem}

The share repaid $\alpha\left(y_{i}, b\right)$ solves the Nash bargaining problem:

$$
\alpha\left(y_{i}, b\right)=\operatorname{argmax}_{\alpha \epsilon[0,1]}\left[\left(\Delta^{B}\left(\alpha ; y_{i}, b\right)\right)^{\theta}\left(\Delta^{L}\left(\alpha ; y_{i}, b\right)\right)^{1-\theta}\right]
$$

subject to $\Delta^{B}\left(\alpha ; y_{i}, b\right) \geq 0, \Delta^{L}\left(\alpha ; y_{i}, b\right) \geq 0$, where $\theta \in(0,1]$ denotes the bargaining power of the borrower, $i=L, M, H$ and $d$ is the debt share covered by CDS.

The surpluses of the borrower and lender are

$$
\begin{gathered}
\Delta^{B}\left(\alpha ; y_{i}, b\right)=u\left(\left(1-c_{a}\right) y_{i}+\alpha b\right)-u\left(\left(1-c_{n a}\right) y_{i}\right), \\
\Delta^{L}\left(\alpha ; y_{i}, b\right)=-\left[\alpha b+p^{\text {trigger }}(\alpha)(1-\alpha) d b\right]-[-d b] .
\end{gathered}
$$

They represent the difference between agreement and no agreement in Figure 2 for the borrower and the lender, respectively. The surplus of the borrower is independent of the level of CDS, since the CDS is paid by a third party. The CDS seller does not hold bonds, so he does not sit at the negotiation table.

The lender's surplus is affected by the existence of the CDS market. Compared to the uninsured lender, the lender with CDS will have a lower surplus for any repayment share $(\alpha)$, since by agreeing to this arrangement the lender is giving up receiving the full CDS payout with certainty. Therefore, the borrower will have to compensate the lender for the uncertainty of the CDS triggering for the agreement to be accepted. This is achieved by increasing $\alpha$, as long as there exists an $\alpha>0$ that gives both the borrower and the lender non-negative surpluses, otherwise the agreement breaks down and the CDS triggers for sure. The lender receives nothing from the borrower and the borrower incurs in higher output costs.

It is important to note that the uncertainty over the CDS paying out is key for the CDS market having an effect on the bargaining outcome. This is easier to see if the surplus of the lender is rewritten separating the CDS covered debt $(d b)$ from the uncovered $(1-d) b$ :

$$
\Delta^{L}\left(\alpha ; y_{i}, b\right)=-b[\underbrace{\alpha(1-d)}_{\text {uncovered }}-\underbrace{\left(1-p^{\text {trigger }}(\alpha)\right)(1-\alpha) d}_{\text {covered }}] .
$$


The term in the first bracket is the extra amount the lender receives by agreeing to the bargaining outcome. The lender gets $\alpha$ per dollar of the uncovered part of the debt from the borrower. To maximize this part of the surplus, the lender wants $\alpha$ to be as high as possible. The term in the second bracket represents what the lender loses by accepting the agreement. This loss is the uncertainty surrounding the CDS payoff, since the renegotiation can be declared as voluntary (not triggering the CDS). If the CDS pays with certainty, there is no loss for the lender from accepting the agreement, so there is no need to compensate with a higher repayment. Formally, I can state this intuition in the following proposition.

Proposition 1: If the CDS always triggers, that is $p^{\text {trigger }}(\alpha)=1$, the level of CDS will not affect the bargaining outcome.

In this case the surplus of the lender becomes $\Delta^{L}(\alpha)=-b[\alpha(1-d)]$ and the bargaining problem can be rewritten as:

$$
\alpha\left(y_{i}, b\right)=\operatorname{argmax}_{\alpha \epsilon[0,1]}\left[\left(\Delta^{B}\left(\alpha ; y_{i}, b\right)\right)^{\theta}\left((1-d) \tilde{\Delta}^{L}\left(\alpha ; y_{i}, b\right)\right)^{1-\theta}\right]
$$

where $\tilde{\Delta}^{L}\left(\alpha ; y_{i}, b\right)=-b \alpha$ is the surplus in the absence of CDS contracts.

\section{Bond and $C D S$ Prices}

Bonds have one-period maturity and are sold at a discount price $q(b)$. Lenders are riskneutral, therefore the price of the debt is just the expected repayment in the next period, taking into account the probability of states of default $\left(\operatorname{def}\left(y_{i}, b\right)=1\right)$ and repayment shares $\alpha\left(y_{i}, b\right)$ in default in case of agreement:

$$
q(b)=\frac{E\left(\operatorname{def}\left(y_{i}, b\right) \alpha\left(y_{i}, b\right)+\left(1-\operatorname{def}\left(y_{i}, b\right)\right) \mid i\right)}{(1+r)} .
$$

The CDS securities are sold under the "points upfront" format where there is a payment upfront $q_{C D S}(b)$ at time of inception (today). The CDS contract also has a one-period maturity. The CDS sellers are risk-neutral, therefore the upfront payment is the expected repayment in case of default, taking into account the probability of the CDS triggering at that level of repayment $\left(p^{\text {trigger }}\left(\alpha\left(y_{i}, b\right)\right)\right)$ :

$$
q_{c d s}(b)=\frac{E\left(\operatorname{def}\left(y_{i}, b\right)\left(1-\alpha\left(y_{i}, b\right)\right) p^{\text {trigger }}\left(\alpha\left(y_{i}, b\right)\right) \mid i\right)}{(1+r)} .
$$


The return on a portfolio of bond and CDS contracts for the holder is

$$
\text { Return }_{\text {portfolio }}=-q(b)-q_{c d s}(b)+1 .
$$

In this portfolio, the investor buys the bond giving the borrower $q(b)$ with the promise to be repaid 1 tomorrow, and buys the CDS paying the seller $q_{c d s}(b)$. To finance this operation the investor short sells (borrows) risk-free bonds, receiving 1 today with the promise to repay $1+r$ the following period.

Plugging in the equations for the prices and setting $r=0$ for simplicity, the portfolio's expected return is

$$
E\left(\left(1-p^{\text {trigger }}\left(\alpha\left(y_{i}, b\right)\right)\left(1-\alpha\left(y_{i}, b\right)\right) \operatorname{de} f\left(y_{i}, b\right) \mid i\right)\right.
$$

If the default probability is zero and/or the CDS always pays out, the return from this portfolio is zero. However when there is some probability of default and uncertainty over the CDS triggering there is an expected positive return from holding this portfolio. The explanation for the positive return is that there are states where the bond gets a haircut but the CDS does not pay out. The same intuiton will explain the negative basis in the dynamic model.

\section{Numerical Exercise}

The model is parametrized to illustrate the effects of the CDS market on debt levels and prices. The mechanism through which CDS contracts affect the size of debt and its price will be the same as in the simple two-period model. Output tomorrow takes the values $y=(0.75,1,1.5)$ with probability distribution $(0.4,0.5,0.1)$. The country has power utility with risk aversion coefficient 2 and no discounting $(\beta=1)$. The bargaining power $\theta$ is 0.5 and the loss of output due to default is $20 \%$ of tomorrow's output if there is an agreement $\left(c_{a}\right)$ and $40 \%$ if there is no agreement $\left(c_{n a}\right)$.

The functional form for the probability of trigger assumed is $p^{\text {trigger }}(\alpha)=\left(1-\alpha^{\kappa}\right)$ with $\kappa \geq 0$, which incorporates the fact that the higher the haircut, the more likely the default will be labeled as a default, and the CDS will pay out. The $\kappa$ parameter is fixed at 1 and the coverage of CDS varies. Figure 3 shows the results. ${ }^{13}$

The solid line in the first quadrant represents the surplus of the borrower, which does not change with CDS and decreases with the repayment share $(\alpha)$, since a higher $\alpha$ means

\footnotetext{
${ }^{13}$ The debt level in the bargaining surplus graph is fixed at 0.15 ( mid debt level).
} 
the borrower is going to have to pay the lender more in the agreement. The surplus of the borrower is for most levels increasing with $\alpha$, since he will get more money back from the borrower.

The higher the level of the CDS, the lower the surplus of the lender, since he has more to lose with the CDS payout uncertainty. Therefore, the higher the CDS, the more the borrower will need to compensate the lender for the uncertainty the lender is incurring by accepting the agreement, resulting in a higher equilibrium repayment share, as can be observed on the lower left graph of Figure 3.

Since in the case of default the borrower needs to repay more, default becomes less attractive and there is a smaller set of states where the borrower decides to default. This is shown in the upper right graph, where the probability of default is the probability of reaching an output state where the decision is to default for a given debt level.

Finally, a lower probability of default plus a higher repayment share in default results in a higher bond price, as shown in the graph in the lower left corner. The higher bond price allows borrowers to hold higher levels of debt (more negative b). The optimal debt choices for each CDS level are displayed in the bond price graph (lower-right graph). The point A represents the optimal debt choice for no CDS, point B for $40 \%$ and point $\mathrm{C}$ for $80 \%$ CDS.

It is important to note that if the CDS is very high, in this example $80 \%$, there will be no level of $\alpha$ for high levels of debt that can give both the lender and borrower positive surpluses, so the equilibrium repayment is zero and the CDS triggers with certainty. The cost of defaulting at high CDS levels is so high ( high $\alpha$ or no agreement output penalty), that the borrower never chooses to default and the bonds become risk-free.

In summary, with the CDS market the equilibrium debt levels are higher and spreads are lower than they would be in a similar model without this market. Also, the possibility of the bond getting a haircut and the CDS not triggering depresses the price of a "CDS-insured bond" relative to the price of the risk-free bond, as observed in the data. The following sections present the full dynamic model and its quantitative implications. 
Figure 3: Numerical Exercise Results
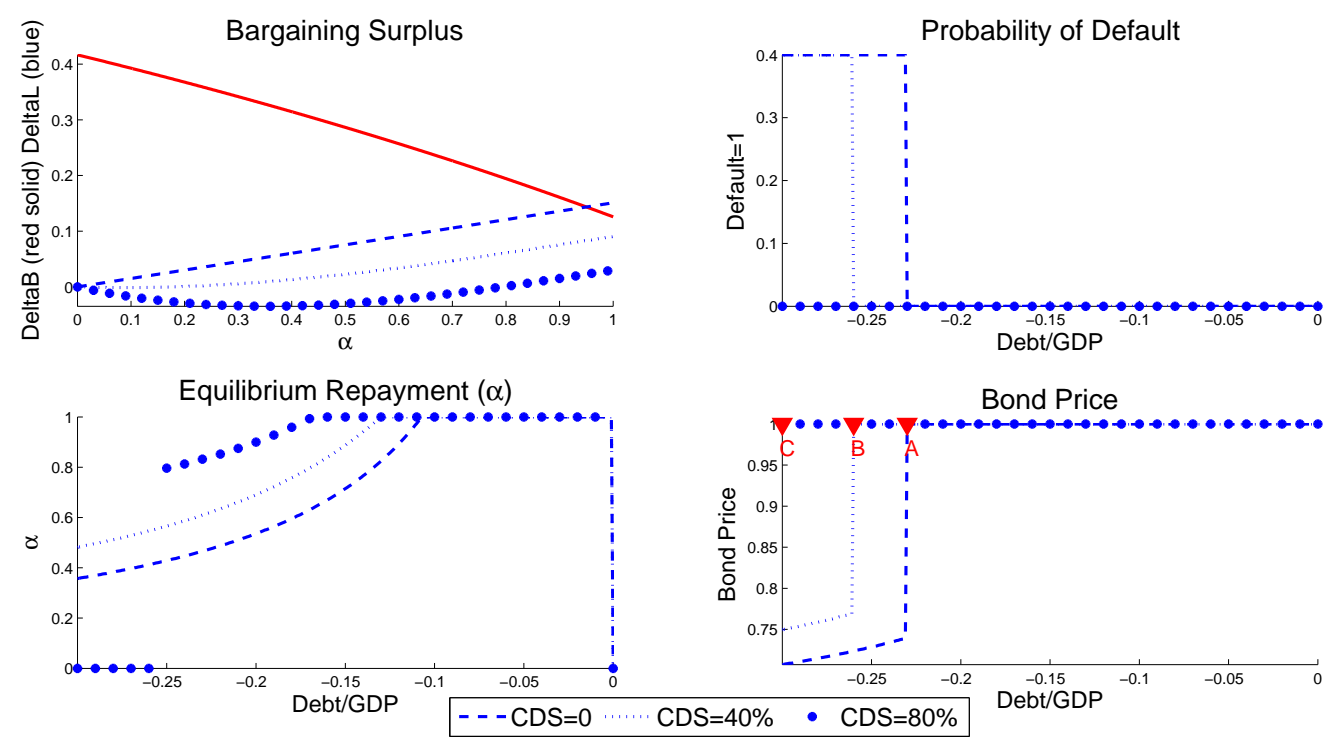

Note: The top left plot displays the borrower and lender surpluses for different levels of CDS. The right top plot, has the country's probability of default at each debt/GDP level, where 1 is default. The bottom right plot shows the equilibrium repayment that results from the bargaining game and the bottom left has bond prices for each debt level and in triangles the optimal debt choice at each CDS level (A is for 0\% CDS, B for $40 \%$ and $\mathrm{C}$ for $80 \%$ ).

\section{The Model Environment}

\section{Preferences and Endowments}

I study the interaction between sovereign default with debt renegotiation and credit default swap (CDS) contracts in a dynamic model of a small open economy. The sovereign country is risk averse and takes the world interest rate as given. The sovereign maximizes expected utility from consumption $c_{t}$ and has preferences given by

$$
\sum_{t=0}^{\infty} \beta^{t} u\left(c_{t}\right)
$$

where $0<\beta<1$ is the discount factor of the sovereign and $u($.$) is continuous, strictly$ increasing, strictly concave, and satisfies Inada conditions.

The model analyzes an endowment economy, where in each period the economy receives a strictly positive exogenous endowment shock $y_{t} \in Y$. The endowment shock is stochastic, has a compact support $Y$ and follows a finite-state Markov process with transition law $\operatorname{Pr}\left\{y_{t+1}=y^{\prime} \mid y_{t}=y\right\}=F\left(y^{\prime}, y\right)$. 


\section{Market Arrangements and Option to Default}

The sovereign can borrow in the international credit market and has the option to default. The country borrows by issuing long-term debt contracts that mature probabilistically (Hatchondo \& Martinez (2009), Arellano \& Ramanarayanan (2012) and Chatterjee \& Eyingungor (2012)). Each unit of outstanding debt matures next period with probability $\lambda$, and if the unit does not mature, which happens with probability $(1-\lambda)$, it pays out a coupon payment $z$. Therefore, if $b$ bonds are outstanding at the start of the period, the issuer's obligations will be $z(1-\lambda) b$ for the coupon payments and $\lambda b$ for the principal. This structure allows targeting maturity length and size of the coupon payments separately. There is only one type of bond $(z, \lambda)$ available in the economy and as is standard in this literature, debt is viewed as a negative asset $(b \leq 0)$.

The international investors are risk-neutral and have perfect information on the country's endowment, debt level and option to default. These investors become lenders to the country by purchasing the sovereign bond in a competitive international bond market. Also, they can borrow or lend as much as needed at a constant international risk-free rate.

If the country decides to default, it stops servicing its debt, discontinuing coupon and principal payments. The default decision comes with penalties. Following a default period the sovereign temporarily loses access to the international credit market staying in autarky, during which period the sovereign loses share $\phi(y)>0$ of the output $y$.

After the default, the country and its bond holders will renegotiate the debt and set the repayment share $(\alpha)$ on each dollar of the defaulted debt. The renegotiated debt will have the same maturity and coupon structure of the original debt and will start to be repaid when the country re-enters the credit markets.

This paper introduces CDS contracts to the sovereign debt analysis. The CDS is modeled as a long-term security with a variable upfront payment at the time of inception and a fixed spread $s$ paid every period by the buyer in case of no default on the sovereign bond. Every period there is a probability $\lambda$ of the contract expiring when it would offer no protection and demand no future spread payments. ${ }^{14}$

If the country and the bond holders accept the terms of the renegotiation, the country will repay $\alpha \in[0,1]$ on each dollar of the defaulted debt to the lenders and the country has a probability to re-enter the international markets with probability $0 \leq \xi<1$ and borrow again. There is a probability that the CDS regulators will consider this a voluntary renegotiation and the CDS will not pay out. If the renegotiation terms are not accepted, the

\footnotetext{
${ }^{14}$ The maturity of the bond and CDS is the same so that we can compare the two assets.
} 
country stays in autarky forever, repays nothing to the lenders and the CDS pays out with certainty.

The country's access to international credit markets is denoted by a discrete variable $h \in\{0,1\}$. Let $h=0$ denote no access to international credit markets, the country is in autarky, cannot save or borrow and makes no debt payments. However, the defaulted debt can be traded in the secondary market and is priced as $q(b, 0, y)$. On the other hand, $h=1$ indicates that the country is able to borrow in the international debt markets by issuing bonds that are sold at the discount price $q(b, 1, y)$. Both prices are determined in equilibrium.

The bond holders buy a fixed share $d$ of the country's debt in CDS contracts. If the sovereign defaults and the CDS regulatory agency decides that the CDS contracts must pay out, the CDS holder is entitled to a payment of $(1-q(b, 0, y))$ on each dollar of covered debt $(d b)$ from the sellers. The CDS sellers are risk-neutral and have perfect information on the country's endowment and debt level. The CDS seller does not participate on the sovereign bond market. Both the CDS seller and the bond investors always keep their promises. ${ }^{15}$

\section{Recursive Equilibrium}

The borrower's infinite horizon decision problem is represented as a dynamic recursive programming problem. Subsection 5.1 analyzes the sovereign government's problem, taking the bond price schedule and the debt renegotiation outcome as given. Subsequently, Subsection 5.2 explains the bond and CDS pricing schedule. Subsection 5.3 explains the debt renegotiation and lender's problem that determine the debt repayment share. Finally, Subsection 5.4 defines the dynamic recursive equilibrium, where prices and debt recovery shares are endogenized.

\subsection{Decision Problem of the Sovereign}

The sovereign government's objective is to maximize the expected lifetime utility of a domestic representative agent. At the beginning of the period, the output shock $y$ is realized and the country has a stock of debt $b$ for which the coupon and principal payments total $(\lambda+(1-\lambda) z) b$. After observing $y$, the government makes its default decision and a debt choice for the next period, where $b \in B=\left[b_{m}, 0\right]$. The $v(b, h, y): B \times\{0,1\} \times Y \rightarrow \Re$ represents the life-time value function for the country that starts with debt $b$, has access $h$ and endowment shock $y$.

\footnotetext{
${ }^{15}$ There is no counterparty risk, so the CDS seller always pay the CDS payout if the credit event is declared.
} 
Define the state space of bond price function as $Q=\left\{q \mid q(b, h, y): B \times Y \rightarrow\left[0, \frac{\lambda+(1-\lambda) z}{r_{f}+\lambda}\right]\right.$ and the state space of the debt repayment share as $A=\{\alpha \mid \alpha(b, y): B \times Y \rightarrow[0,1]\}$. Given any bond price function $q \in Q$ and repayment share $\alpha \in A$, the country solves its optimization problem.

For $h=1$, the country has access to the international credit markets and has to decide to default or not optimally. The value of the option to default is given by:

$$
V(b, 1, y)=\max \{v(b, 1, y), v(b, 0, y)\}
$$

Where $v(b, 1, y)$ is the value associated with not defaulting and keeping access to the credit markets and $v(b, 0, y)$ is the value associated with default.

The country's payoff from repaying the debt is the following:

$$
\begin{gathered}
v(b, 1, y)=\max _{b^{\prime} \epsilon B} u(c)+\beta E_{y^{\prime} \mid y} V\left(b^{\prime}, 1, y^{\prime}\right) \\
\text { s.t. } c \leq y+[\lambda+(1-\lambda) z] b+q\left(y, 1, b^{\prime}\right)\left[(1-\lambda) b-b^{\prime}\right] .
\end{gathered}
$$

If $\left[(1-\lambda) b-b^{\prime}\right] \geq 0$, the borrower issues new debt, increasing the debt stock. If $\left[(1-\lambda) b-b^{\prime}\right]<$ 0 , the country buys back bonds before they mature, meaning there will be less debt to service next period. The country's consumption is the endowment minus the debt service $([\lambda+(1-\lambda) z] b)$ plus the change in the debt stock at the price of $q\left(y, 1, b^{\prime}\right)$. If all choices of $b^{\prime}$ lead to negative consumption, repaying is not a feasible option, in which case the value of repaying $v(b, 1, y)$ is set to $-\infty$. If repayment is feasible, the optimal debt choice of the sovereign is denoted $a(b, y) .{ }^{16}$

The value of default is defined as:

$$
v(b, 0, y)=u(y-\phi(y))+\beta E_{y^{\prime} \mid y}\left\{[1-\xi] v_{\bar{y}=y}\left(b, 0, y^{\prime}\right)+\xi V\left(\alpha(b, y) b, 1, y^{\prime}\right)\right\}
$$

where

$$
v_{\bar{y}}(b, 0, y)=u(y-\phi(y))+\beta E_{y^{\prime} \mid y}\left\{[1-\xi] v_{\bar{y}}\left(b, 0, y^{\prime}\right)+\xi V\left(\alpha(b, \bar{y}) b, 1, y^{\prime}\right)\right\}
$$

When the borrower defaults, output falls by $\phi(y)$ and the economy is temporarily in autarky; $\xi$ represents the probability that it will regain access to international credit markets each

\footnotetext{
${ }^{16}$ If the sovereign is indifferent between two debt choices, it chooses the lower debt level (i.e. largest value).
} 
period. Once the country re-enters the market, it has to repay the renegotiated debt, $\alpha(b, y) b$, which is the result of a bargaining game to be described in subsection 5.3. The renegotiated debt will have the same maturity and coupon structure as the original debt. The debt is only renegotiated once, at the time of default, and $\alpha(b, y)$ depends of the debt and output at time of default $(\bar{y})$.

In case the sovereign is indifferent between defaulting and repaying, it repays. Therefore default happens if and only if $v(b, 1, y)>v(b, 0, y)$. The decision problem implies a default decision $\operatorname{de} f(b, y)$ (where $\operatorname{de} f=1$ is default and $\operatorname{de} f=0$ repayment) and in the region where repayment is feasible, a debt decision rule $a(b, y)$ and a repayment share policy $\alpha(b, y)$.

\subsection{Bond and CDS Prices}

\section{Bond Prices}

The prices are determined for any repayment share $\alpha \in A$, an optimal default decision de $f(b, y)$ and debt decision rule $a(b, y)$ from the sovereign problem. The one period risk-free rate $\left(r_{f}\right)$ is taken as exogenous. Due to a competitive market in the sovereign debt market, the unit price of a bond, $q\left(b^{\prime}, 1, y\right)$, must be consistent with zero profits adjusting for both the probability of default and the repayment share. Since there is repayment on the defaulted debt, there is also a market price for this debt. Let $q(b, 0, y)$ be the price for a unit of the defaulted bond when the total number of defaulted bonds outstanding is $b$ and the output is $y$.

For risk-neutral investors, the price of a unit of bond satisfies the following equation:

$$
q\left(b^{\prime}, 1, y\right)=E_{y^{\prime} \mid y}\left[\left(1-\operatorname{def}\left(b^{\prime}, y^{\prime}\right)\right) \frac{\lambda+(1-\lambda)\left[z+q\left(a\left(b^{\prime}, y^{\prime}\right), 1, y^{\prime}\right)\right]}{1+r_{f}}+\operatorname{def}\left(b^{\prime}, y^{\prime}\right) \frac{q\left(b^{\prime}, 0, y^{\prime}\right)}{1+r_{f}}\right]
$$

In repayment, the bond holders get paid the face value of the matured bonds and the coupon payment $z$ from the bonds that have not yet matured. If a bond has not matured, it will pay coupon/principal in future periods, therefore investors can sell this security for the price of $q\left(a\left(b^{\prime}, y^{\prime}\right), 1, y^{\prime}\right)$. In default, the investor will get a share of the debt repaid, therefore the defaulted bond will be worth $q\left(b^{\prime}, 0, y^{\prime}\right)$.

The market price of one unit of defaulted debt, under competition, needs to take into account that the agreed upon repayment at the time of renegotiation will only start to be repaid when the country reenters the international credit market (which happens with 
probability $\xi$ ). Therefore, there is the possibility of immediate default by the sovereign upon reentry into the market (once repayment starts). Hence, the market price of a unit of defaulted debt will satisfy the following functional equation:

$$
q(b, 0, y)=E_{y^{\prime} \mid y}\left\{(1-\xi)\left[\frac{\left.q\left(b, 0, y^{\prime}\right)\right]}{1+r_{f}}\right]+\xi\left[\alpha(b, y) q\left(\alpha(b, y) b, 1, y^{\prime}\right)\right]\right\}
$$

Observe that $\alpha(b, y)$ is less or equal to one, therefore a unit of defaulted bond will, upon settlement, become less than a unit of the restructured debt. The $\xi$ adjusts for the fact that the country only repays when it regains access to the market. The restructured debt will be risky, since the choice to default again is available, therefore its value is $q\left(\alpha(b, y) b, 1, y^{\prime}\right)$.

One interesting feature of this setup is that when negotiating the lender is not only worried about getting a high recuperation value $\alpha(b, y)$, but also about the market value of the restructured debt $(q(b, 0, y))$. If a high $\alpha(b, y)$ implies that the country will not be able to repay that amount when it re-enters the market, the market value of this repayment will be low.

\section{CDS Prices}

The CDS contract is modeled as a long-term contract that matures probabilistically, with a fixed spread paid every period. The contract will be priced under the "points upfront" format, where there is a payment upfront $q_{C D S}\left(b^{\prime}, y\right)$ at time of inception, and a fixed spread $s$ paid every period in case of no default up to maturity. To model the maturity of the CDS, every period there is a probability $\lambda$ of the contract expiring after which point it would offer no protection and demand no future spread payments. ${ }^{17}$ If the contract does not expire it will payout $(1-q(b, 0, y))$ for each unit of CDS covered debt when the ISDA determines default and that the CDS will trigger.

The CDS can be quoted in two formats: points upfront or running spread. ${ }^{18}$ As discussed above, in the points upfront format there is an initial payment in the time of inception and then a fixed spread payed quarterly until maturity. In all the CDS contracts traded this way, the spread is constant and the upfront payment varies to adjust for the riskiness of the underlying contract (the sovereign bond in this case). For the running CDS there is no payment at time of inception, only a spread that is fixed at that time. The choice to model the contracts as points upfront is due to the fact that with fixed coupons it is easier to keep

\footnotetext{
${ }^{17}$ The maturity of the CDS is the same as the bond's so that they are comparable securities.

${ }^{18}$ After the CDS Big Bang of April 2009, all single name CDS in North America were traded as upfront contracts with fixed coupon. For Europe, this happened after the CDS Small Bang of June 2009.
} 
track of the contracts in the computation. This choice does not affect the results as the points upfront contracts can be converted into running spreads. ${ }^{19}$

When pricing the CDS contract it is important to consider: (1) the probability of the country defaulting $($ def $=1)$; (2) the probability of the CDS triggering (trig = 1); and (3) the repayment share post default $(\alpha)$. Table 1 shows the CDS payout for each scenario.

Table 1: CDS Payout

\begin{tabular}{ccc}
\hline & trig $=1$ & trig $=0$ \\
\hline def $=1$ & $(1-q(b, 0, y))$ & 0 \\
def $=0$ & $-s+q_{C D S}\left(a\left(b^{\prime}, y^{\prime}\right), y^{\prime}\right)$ & $-s+q_{C D S}\left(a\left(b^{\prime}, y^{\prime}\right), y^{\prime}\right)$ \\
\hline
\end{tabular}

Note: Table 1 shows the possible payoff of the CDS which depends on default $\in(0,1)$ and CDS triggering $\in(0,1)$.

The price of a unit of CDS follows the premise that at time of inception:

Total value of expected premiums=Expected value of default payment.

Therefore, the upfront payment of the CDS satisfies the following equation:

$q_{C D S}\left(b^{\prime}, y\right)=\frac{(1-\lambda) E_{y^{\prime} \mid y}\left\{\left(1-\operatorname{def}\left(b^{\prime}, y^{\prime}\right)\right)\left(q_{C D S}\left(a\left(b^{\prime}, y^{\prime}\right), y^{\prime}\right)-s\right)+\operatorname{de} f\left(b^{\prime}, y^{\prime}\right) p^{\text {trigger }}(1-q(b, 0, y))\right\}}{1+r_{f}}$

\section{CDS-Bond Basis}

The bond spread is calculated in the model as is calculated in the data. Given the unit price $q\left(b^{\prime}, 1, y\right)$ of the outstanding bonds, an internal rate of return is computed, $r\left(b^{\prime}, y\right)$, which matches the present discounted value of the promised sequence of payments to the price. That is:

$$
q\left(b^{\prime}, 1, y\right)=\frac{\lambda+(1-\lambda) z}{\lambda+r\left(b^{\prime}, y\right)}
$$

\footnotetext{
${ }^{19}$ When comparing to the data and calculating the basis, the points upfront contracts are converted into running, in order to compare to the data (the data is usually quoted in running).
} 
Therefore the annualized bond spread in the model is $s_{b o n d}=\left(1+r\left(b^{\prime}, y\right)\right)^{4}-\left(1+r_{f}\right)^{4}$.

To calculate the basis, it is necessary to transform the points upfront contract into a running spread quote. The expected value of default payment is the same as before. Hence, it is only necessary to find what is the running spread that has the same present value of the expected value of the premium on the upfront contract. This is given by the following equation:

$$
s^{R}=\frac{(r+\lambda) q_{C D S}\left(b^{\prime}, y\right)}{(1-\lambda)}+s
$$

The annual CDS running spread is: $s_{c d s}=\left(1+s^{R}\right)^{4}-1$. The model CDS-Bond basis is defined as: basis $=s_{c d s}-s_{\text {bond }}$.

\subsection{Debt Renegotiation Problem}

If a country defaults, the sovereign government and the bond holders renegotiate over the debt reduction. This renegotiation defines how much of the defaulted debt will be repaid by the country to the lenders. This restructured debt will start being serviced once the country regains access to the international markets.

The renegotiation is modeled as a one-shot Nash bargaining game. The threat points of the bargaining game are: if there is no agreement the borrower stays in autarky forever and the lenders get nothing from the country but the CDS triggers with certainty. Permanent autarky implies no access to capital markets and direct output loss for the country. The expected value of autarky to the country, $v_{a u t}(y)$ is:

$$
v_{a u t}(y)=u(y-\phi(y))+\beta E_{y^{\prime} \mid y} v_{a u t}\left(y^{\prime}\right)
$$

The surplus of the borrower, for any debt recovery function $\alpha \in A$, is the difference between the value of accepting the deal and the value of rejecting it. The country's surplus is denoted by $\Delta^{B}(\alpha ; b, y)$, which is a function of recovery rate $\alpha$, given amount of defaulted debt $b$ and endowment at time of default $y$.

$$
\Delta^{B}(\alpha ; b, y)=\left\{\begin{array}{cc}
{\left[u(y-\phi(y))+\beta E_{y^{\prime} \mid y}\left\{[1-\xi] v_{\bar{y}=y}\left(b, 0, y^{\prime}\right)+\xi V\left(\alpha b, 1, y^{\prime}\right)\right\}\right]-v_{a u t}(y)} & \text { if } \alpha>0 \\
0 & \text { if } \alpha=0
\end{array}\right.
$$


The first term is the expected value of defaulting when the repayment share is $\alpha$. The surplus of the borrower comes from the fact that the expected length of exclusion from credit markets is finite. Therefore, by repaying something to the borrower, the country gains access to the international credit markets at some point in the future.

The surplus of the risk-neutral lender, for any debt recovery function $\alpha \in A$ is:

$$
\Delta^{L}(\alpha ; b, y)=-b\left[q(b, 0, y)+d(1-q(b, 0, y)) p^{\text {trigger }}\right]-[-b d]
$$

where $b$ is the debt defaulted and $q(b, 0, y)$ is the value of a unit of that debt in the market. This value incorporates not only the share the country repays but also the probability that this will be repaid. The CDS coverage share of the debt is represented by $d$, which is a fixed parameter.

If lender and borrower reach an agreement, the lender gets the recovery value from the country for the entire debt stock and with a probability $p^{\text {trigger }}$, the CDS triggers and the CDS buyer receives $(1-q(b, 0, y))$ for the CDS covered debt. In case there is no agreement, the lender gets the CDS payout with certainty for the CDS covered debt and nothing from the country.

If the lenders have full bargaining power, they can extract debt payments up to the full amount of the country's cost of default. On the other hand, if the country has all the bargaining power, it would choose to repay a value close to zero that would still allow it to regain access to the international markets in the future. Assume that $0<\theta<1$ is the bargaining power of the borrower and $(1-\theta)$ the bargaining power of the lender. Given a debt level $b$ and an endowment $y$, the debt recovery rate, $\alpha(b, y)$ solves the following bargaining problem:

$$
\begin{gathered}
\alpha(b, y)=\operatorname{argmax}_{\alpha \in[0,1]}\left[\Delta^{B}(\alpha ; b, y)^{\theta}\left(\Delta^{L}(\alpha ; b, y)\right)^{1-\theta}\right] \\
\text { s.t. } \Delta^{B}(\alpha ; b, y) \geq 0 \\
\Delta^{L}(\alpha ; b, y) \geq 0 .
\end{gathered}
$$

The CDS contracts only affect the surplus of the lender, since the CDS payout comes from a third party that does not participate in the renegotiation. The lender's surplus is affected in two ways. First, for any $\alpha$ the CDS contract makes the surplus of the lender lower. 
Second, there will be zones where the only $\alpha$ that satisfies the non-negative constraints will be $\alpha=0$, since a low $\alpha$ may make the lender's surplus negative because he prefers that the CDS triggers with certainty.

\subsection{Equilibrium Definition}

Definition 1 A recursive equilibrium is a set of functions for (i) the sovereign government's value function $v^{*}(b, h, y)$, asset holdings $b^{*}(b, y)$, consumption $c^{*}(b, h, y)$, and default set $d e f^{*}(b, y)$,(ii) repayment share $\alpha^{*}(b, y)$, and (iii) pricing functions $q^{*}\left(b^{\prime}, h, y\right)$ and $q_{C D S}^{*}\left(b^{\prime}, y\right)$ such that:

1. Given the bond pricing function, $q^{*}\left(b^{\prime}, h, y\right)$, recovery share $\alpha^{*}(b, y)$, the value function $v^{*}(b, h, y)$, consumption $c^{*}(b, h, y)$, asset holdings $b^{*}(b, y)$, and default sets de $f^{*}(b, y)$ satisfy the country optimization problem.

2. Given the bond pricing function, $q^{*}\left(b^{\prime}, h, y\right)$, value function $v^{*}(b, h, y)$, and repayment rates $\alpha^{*}(b, y)$ solve the debt renegotiation problem.

3. Given $\alpha^{*}(b, y)$, bond price function $q^{*}\left(b^{\prime}, h, y\right)$, and CDS price function $q_{C D S}^{*}\left(b^{\prime}, y\right)$ satisfy the zero expected profit condition for the investors and CDS seller, where the default probabilities and expected recovery rates are consistent with the repayment policy and renegotiation agreements.

The equilibrium is subgame perfect since: (a) the government, bond holders and CDS sellers take the debt repayment share function as given and behave optimally; and (b) the repayment share solves the ex post debt renegotiation after default.

\section{Quantitative Analysis: The Greek Case}

The model is applied to Greece, the country that most recently had a default event with significant uncertainty over the triggering of the CDS contracts. In subsection 6.1 the model is calibrated for Greece without the existence of the CDS market. Subsection 6.2 describes the calibration of the CDS market. Subsection 6.3 presents simulation results and analyzes the effects of different CDS levels. Finally subsection 6.4 discusses welfare implications. 


\subsection{Calibration with no CDS market}

The model period is defined as one quarter. The utility function for the sovereign government is a constant relative risk aversion (CRRA) with curvature parameter $(1-\sigma)$,

$$
u(c)=\frac{c^{1-\sigma}}{1-\sigma}
$$

where the coefficient of risk aversion $\sigma$ is set at 2 , the frequently used value in the literature.

The endowment process is calibrated to the Greek output. The stochastic process for output is a log-normal AR(1) process:

$$
\log \left(y_{t+1}\right)=\rho \log \left(y_{t}\right)+\epsilon_{t+1}
$$

with $E\left[\epsilon^{2}\right]=\eta^{2}$. The process is discretized into a fifteen-state Markov chain using a quadrature based procedure (Tauchen and Hussey (1991)). Seasonally adjusted and linearly detrended real GDP series for the period of 2000Q1 to 2012Q4 from the Hellenic Statistical Authority (EL.STAT) is used as quarterly output data. ${ }^{20}$ The estimated values of $\rho$ and $\eta^{2}$ are 0.934 and $0.03^{2}$, respectively. ${ }^{21}$

The quarterly risk-free interest rate $r_{f}$ is set to $1 \%$, which corresponds to an annual rate of $4 \%{ }^{22}$ The parameters describing the bond were determined to match the maturity and coupon information for Greece. The bond maturity was set to 20 quarters, since this is the most liquid CDS market and the maturity of CDS was set equal to the bond's. ${ }^{23}$ Therefore, $\lambda=1 / 20=0.05$. The quarterly coupon rate $z$ is set to $1.25 \%$ which is equivalent to a coupon rate of $5 \%$ per annum. This is equal to the average coupon for 5-year Greek government bonds issued between 2003 and 2010 .

The re-entry probability is fixed as $\xi$ if the repayment share post default is not zero $(\alpha>0)$ and zero for $\alpha$ equals zero. Cruces and Trembesch (2013), using data from 1970 to 2010, estimate that the average time between restructuring and access to the market is

${ }^{20}$ The GDP data were deseasonalized using the multiplicative X-12 routine.

${ }^{21}$ I use numerical techniques to solve the model. In models of endogenous default with long-term debt the problem of non-convergence is specially frequent. I use the algorithm developed in Chatterjee and Eyigungor (2012) to generate convergence. The algorithm relies on the introduction of economically small i.i.d. continuous shocks to output that smooth the default decision. This shock is taken into account when parametrizing the income process. I assume a shock with standard deviation of 0.006 , adjusting the persistance and standard deviation to 0.9389 and 0.02797 respectively.

${ }^{22}$ This is approximately the average 5 year rate of the German government bond for the period of 1993 to 2012 .

${ }^{23}$ There is not much data on maturity of the external debt for Greece. The OECD data estimates an average maturity of total debt of about 7.25 year 
5.1 years, therefore $\xi$ is set to 0.0492. Following Arellano (2008), I assume that the form of the default output $\operatorname{cost} \phi(y)$ is $\max \left(0, y-y_{\text {def }}\right)$, where $y_{\text {def }}=(1-\delta) E(y)$. This type of cost of default is based on evidence that (1) sovereign default disrupts the functioning of the financial private sector, diminishing the aggregate credit available in the economy, and (2) private credit is an essential input for production. Rose (2005) finds that bilateral trade drops by approximately $8 \%$ per year following the occurrence of a sovereign default.

There are three parameters left: sovereign discount factor $\beta$, output loss after default $\delta$ and bargaining power of the borrower $\theta$. These are determined jointly to match three moments of the Greek data: average default frequency, debt repayment share post default and average annualized spread in the 5-year Greek government bond. Reinhart and Rogoff (2010) record two episodes (including the predicted 2012 one) of sovereign defaults in Greece's external debt since 1934, making its average default frequency $2.6 \%$ annually. The package offered in exchange for the restructuring of the debt consisted of paying 46.5 cents on the dollar, totaling a haircut of 53.5. ${ }^{24}$ Finally, the average annualized spread in the 5-year Greek sovereign bond over the German sovereign bond of the same maturity from 2000Q1 to $2011 \mathrm{Q} 4$ is 204 basis points.

I impose the constraint that if $\left[(1-\lambda) b-b^{\prime}\right]>0$ (i.e. the borrower is issuing bonds), $E_{y^{\prime} \mid y} \operatorname{def}\left(y^{\prime}, b^{\prime}\right)$ cannot exceed a value $\tau \in(0,1)$. This value is set to $\tau=0.75$, which imposes that the borrower cannot issue new bonds if the implied annualized default probability of the new debt level is higher than 99.61\%. As discussed by Chatterjee and Eyigungor (2013), in a model with long-term bonds and recovery post-default, as the one in this paper, default is generally preceded by maximum dilution (see section 4.2 of their paper for the logic). ${ }^{25}$ Since in reality maximum dilution is not observed, there must be a real world constraint that prevents this behavior. The authors propose that a possible constraint would be underwriting standards, which would impose this upper bound on the ex-ante probability of default on a new issue of bonds. The parameters are summarized in Table 2 .

Other moments that I do not target but are important in the model are debt to GDP ratio, volatility of consumption and spreads, and the business cycle correlations of consumption and spreads. These statistics and their model counterparts are reported in Table 3. The debt level in the data is the external long term debt for Greece.

\footnotetext{
${ }^{24}$ The package had 3 type of bonds: (i) One and two year notes issued by the EFSF, amounting to $15 \%$ of old debt face value; (ii) 20 new Greek government bonds maturing between 2023 and 2042, amounting to 31.5 cents on the old debt face value; and (iii) a GDP linked security which could provide extra payment stream up to one percentage point of the face value of the new outstanding bonds.

${ }^{25}$ Maximum dilution means that before defaulting the borrower always goes to the maximum amount of debt allowed in the model.
} 
Table 2: Parameter Values

\begin{tabular}{lll}
\hline & Value & Target \\
\hline Parameters Selected Independently & \\
\hline Risk-free Rate & $r_{f}=0.01$ & Interest Rate on the German 5 year bond \\
Borrower's Risk Aversion & $\sigma=2$ & \\
Reciprocal of Avg Maturity & $\lambda=0.05$ & \\
Coupon Payments & $z=0.0125$ & Average Greek 5 year bond coupon \\
Stochastic Structure & $\rho=0.934$ & Greece's output \\
Probability of Re-entry & $\eta=0.03$ & Cruces and Trembesch $(2011)$ \\
\hline Jointly Calibrated Parameters & & \\
\hline Default Cost & $\delta=0.0492$ & \\
Borrower's Discount Factor & $\beta=0.972$ & Greece average 5 -year spread of $2 \%$ \\
Borrower's Bargaining Power & $\theta=0.86$ & Debt Repayment Share of 46.5 cents/dollar \\
\hline
\end{tabular}

Note: The parameters selected independently are based on data for Greece or on previous studies.The other parameters are jointly calibrated to match moments on Greek data.

\begin{tabular}{lrr}
\multicolumn{2}{c}{ Table 3: Non } & Targeted \\
\hline Moment & Data & Model \\
\hline Debt $/ \mathrm{GDP}^{*}$ & $77 \%$ & $74 \%$ \\
$\sigma\left(r-r_{f}\right)^{*}$ & $5 \%$ & $5 \%$ \\
$\sigma(c) / \sigma(y)$ & 0.98 & 1.01 \\
$\operatorname{corr}(c, y)$ & 0.97 & 0.98 \\
$\operatorname{corr}\left(r-r_{f}, y\right)$ & -0.59 & -0.40 \\
\hline
\end{tabular}

*Sample period: 2003Q2 to 2011Q4

All other moments 2000Q1 to 2012Q4

Note: This table compares moments of Greece that were not targeted in the model to the data.

\subsection{Calibration of the CDS market}

In this section, CDS is added to the model. The non-CDS related parameters are set to be equal to the ones in the no-CDS model (Table 2), so the two set-ups only differ on the existence of the CDS market. To add the CDS market to the model, two more parameters need to be defined: the fixed spread paid to the CDS seller every period $(s)$ and the maturity 
of the CDS $(\lambda)$. To be able to compare the spreads of the CDS and the bond, the maturity of the CDS is set to 5 years. This maturity is the most liquid CDS contract. The spread paid to the seller is set at 25 basis points per quarter, adding to 100 basis points per year. This is one of the standarized spreads defined by ISDA in 2009. ${ }^{26}$ The results assume different levels of CDS $(d)$, including the $5 \%$ observed in the data.

The probability of triggering is a function of the market value of the defaulted debt

$$
p^{\text {trigger }}(b, y, \alpha)=1-q(b, 0, y)^{\kappa} \text {. }
$$

This equation captures parsimoniously the following ideas: (a) if the value of the restructured debt is low, the probability the renegotiation outcome is categorized as a credit event is high; (b) if the market value of the restructured debt is very high (small haircut), the probability that the credit event is declared (and the CDS pays out) is low.

The probability of triggering is an indirect function of $\alpha(b, y)$, the face value of the restructured debt. If there is an agreement after the renegotiation, the country will have a new debt level $\alpha b$ to be repaid when it re-enters the financial markets. Since the country can default on its debt once it does re-enter, the lender values the repaid debt as $q(b, 0, y) b$ which is dependent on $\alpha(b, y)$ (see equation (5)).

The CDS seller repays the CDS buyer $(1-q(b, 0, y))$ for each dollar of CDS insured debt, if the credit event is declared. Therefore, the investor that holds the CDS and the bond gets the full face value of the defaulted debt. In the case of Greece, $\alpha=46.5$ and the market value of the restructured debt was $q(b, 0, y)=21.7$, since there was a high risk that Greece will default on the restructured debt.

The $\kappa$ parameter controls the sensitivity of the probability of triggering to the market haircut. The lower $\kappa$, the lower the probability of the default being considered a credit event, for any repayment value $q(b, 0, y)$. For example, if the country repays 20 cents on the dollar after default, the probability of the CDS triggering is $15 \%(\kappa=0.1), 74.5 \%(\kappa=0.85)$ and $100 \%(\kappa=5)$. This parameter can be interpreted as the market expectation over the probabilty of ISDA declaring the renegotiation a credit event given different levels of repayment. ${ }^{27}$

This parameter affects the CDS-Bond basis level predicted by the model. The triggering probability defines the difference in the price of insurance and bond when the probability of

\footnotetext{
${ }^{26}$ The ISDA Small Bang of June 2009 standardized coupon values at 25, 100, 500 and 1000 basis points.

${ }^{27} \mathrm{~A}$ high $\kappa$ is the market expecting ISDA to almost always triggering the CDS and a low one a hard to trigger ISDA.
} 
Table 4: Parameter Values

\begin{tabular}{|c|c|c|}
\hline & Value & Target \\
\hline \multicolumn{3}{|c|}{ Parameters Selected Independently } \\
\hline Reciprocal of Avg Maturity & $\lambda=0.05$ & Most liquid CDS \\
\hline CDS Spread & $s=25 b p$ & ISDA Bang \\
\hline Level of CDS & $d=[5 \%, 25 \%, 40 \%]$ & \\
\hline \multicolumn{3}{|l|}{ Calibrated Parameters } \\
\hline Triggering Function & $\kappa=0.85$ & Avg. Basis $=-116 \mathrm{bp}$ \\
\hline
\end{tabular}

Note: The parameters selected independently are based on data for Greece or on previous studies.The other parameter is calibrated to match moments on Greek data.

default is not zero. If the CDS almost always triggers (i.e. $\kappa$ is high), these two securities will have very similar prices, making the basis small in absolute value (close to zero). If the CDS almost never triggers (i.e. $\kappa$ is low, less than 1), the basis will large in absolute value and negative, since a insurance that never pays should be cheap. The parameter is calibrated such that the average CDS-bond basis in the model with 5\% CDS-debt level simulated with the realized Greek output shocks is equal to -116 basis points, the average Greek basis between 2008Q2 to 2011Q1. The $\kappa$ value that matches this moment is $\kappa=0.85{ }^{28}$ The parameters for the CDS market are summarized on Table 4.

\subsection{Results}

Two sets of results are presented. First, the stationary equilibrium for different levels of CDS is compared to the one with no-CDS market. This is achieved by solving the model with CDS-debt levels of 5\%, 25\% and $40 \%$ and simulating with the same shock sequence as the one without CDS. The results are presented in Table 5. Next, the model with 5\% CDS-covered debt is simulated with the realized income shocks for Greece starting at 2008. Figure 4 compares the realized basis to the model generated one. ${ }^{29}$

If there is some uncertainty over the CDS triggering after the renegotiation is complete, such as with $\kappa=0.85,5 \%$ CDS covered debt already changes the equilibrium repayment. Since there is some probability that the insurance payment will not be triggered after renegotiation, the lender has significant expected losses even at low levels of insurance. Therefore, lenders demand higher repayment to compensate for their expected losses in their CDS holding from accepting the renegotiation. Default when lenders hold CDS is more costly, so countries can credibly commit to default in a smaller set of states. Hence, given a state

\footnotetext{
${ }^{28}$ See subsection 6.3 and appendix B for more detail on the relationship of the basis and the parameter $\kappa$

${ }^{29}$ Plots and tables for $\kappa=5$ and $\kappa=0.1$ are in the appendix B
} 
$(b, y)$, higher repayment and lower default probability leads to a lower spread in equilibrium.

At 5\% and 25\% CDS, since the country's debt choice does not significantly change from the no CDS case, the higher commitment decreases the equilibrium average spread. Even though the country chooses to incur slightly less debt, it achieves higher average consumption, because it can borrow at a lower rate (i.e., the same debt level yields higher consumption).

When the level of CDS increases to $40 \%$, the country borrows more, increasing debt levels by $15 \%$. This is due to the fact that for a given debt level it can commit to repayment at even more states than at lower levels of CDS, lowering spreads significantly. Since debt levels are endogenous, the country chooses to take advantage of the lower spreads to borrow more. At a higher debt level, the set of states where you would choose to default is larger so higher debt also comes with higher probability of default ${ }^{30}$. Because you default more often, the average consumption is lower than in the case without CDS.

\begin{tabular}{|c|c|c|c|c|}
\hline & No $C D S$ & $5 \% C D S$ & $25 \% C D S$ & $40 \% C D S$ \\
\hline Repayment (\%) & 94.5 & 95 & 97.5 & 97.5 \\
\hline Repayment in Default (\%) & 46.5 & 47 & 49.1 & 51.7 \\
\hline Probability of Default (\%) & 2.58 & 2.0 & 2.1 & 3.11 \\
\hline Debt/GDP (\%) & 74.7 & 74.5 & 74.7 & 87 \\
\hline Bond Spread (\%) & 2.03 & 1.54 & 1.55 & 2.36 \\
\hline Avg. Consumption & 0.9917 & 0.9925 & 0.9923 & 0.9888 \\
\hline
\end{tabular}

Note: The moments are calculated from 1000 simulations of 1000 observations each. In each simulation, the model is simulated for 5000 periods and the first 4000 observations excluded. Repayment is presented as an unconditional average (Repayment) and conditional on default (Repayment in Default).

In the simulation with the realized income shocks for Greece, default happens in 2012Q1, same time when the renegotiation for Greece was completed and CDS triggered. As it can be observed in Figure 4, the model-simulated basis follows the dynamic of the data very closely. Two patterns are stricking: (a) the lower the GDP the more negative is the basis; (b) the reversal when GDP is at a very low level.

As output declines, the probability of default increases and the share repaid in default decreases. If there is a default, there is a probability that the bond will get a haircut and the CDS will not trigger (specially if the level of repayment in default is high), making the basis negative. Therefore, the higher the probability of default the more negative should the basis

\footnotetext{
${ }^{30}$ If the average debt level is fixed at similar levels to the No CDS (74.7\%), the probability of default would be lower than $2.1 \%$.
} 
be. The reversal comes from the fact that the lower the income the lower is the equilibrium repayment in default. The lower the repayment in default, the higher the probability of the CDS triggering when there is a default. When output is very low, the uncertainty of whether the CDS will trigger in the case of a default decreases, creating the reversal. Even thought, the level of the basis is calibrated to match the data, the fact that the model is able to generate the same dynamics of the basis illustrates the success of the mechanism.

Figure 4: CDS-Bond basis: Data vs. Simulated Results

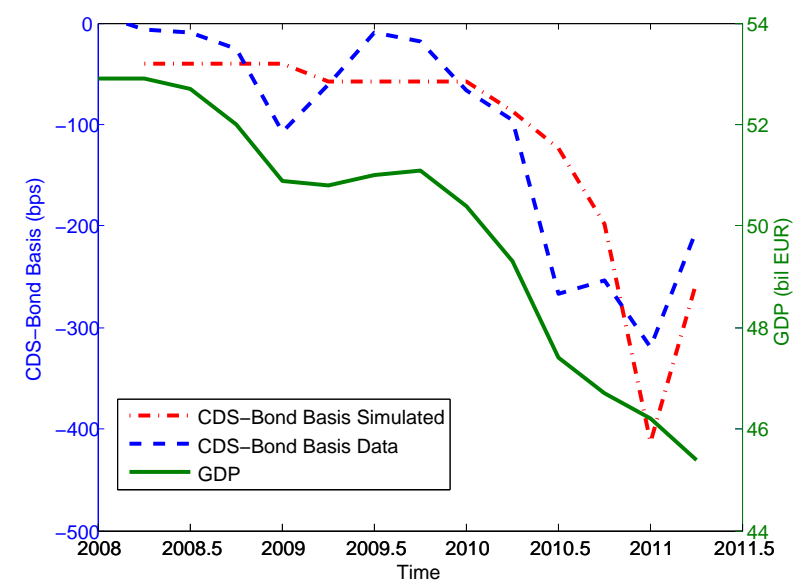

Note: The figure shows simulation results for the basis using the actual Greece output between 2008Q1 and 2011Q2 on the model with 5\% CDS-debt level. The simulated basis is compared to data on the left axis. The right axis plots the real GDP for Greece in billions of euros. The output data is seasonally adjusted.

\subsection{Welfare Gain from the CDS Market:}

Welfare is measured as the constant proportional change in consumption that would leave the country indifferent between no CDS and different levels of CDS. Given the utility function, welfare is computed as

$$
E V(b, y)=\left[\frac{V_{C D S}(b, y)}{V_{N o C D S}(b, y)}\right]^{\frac{1}{(1-\sigma)}}-1
$$

There are several forces affecting the welfare. First, CDS increases the debt repayment share in default, making default a more costly choice. By how much the repayment share increases will depend on the level of CDS. Higher levels of CDS covered debt leads to a 
Figure 5: CDS Welfare Change \%

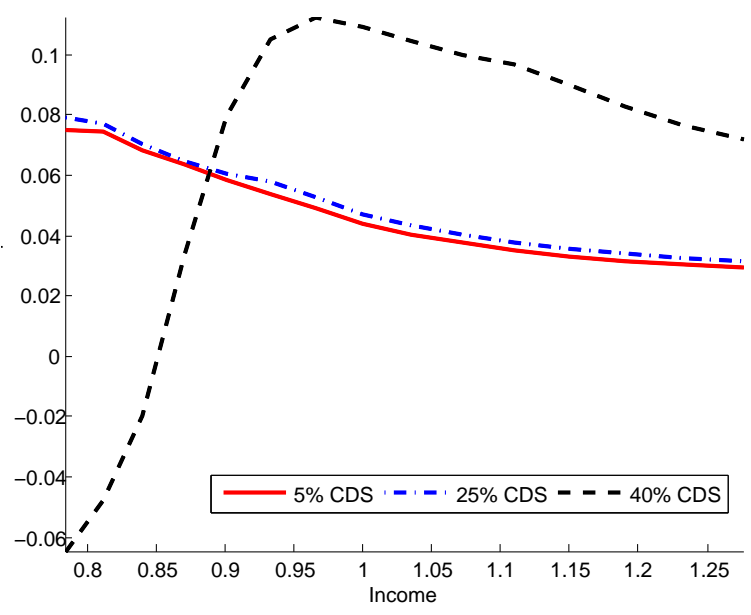

Note: This figure displays welfare gain in \% from the introduction of CDS at 5\%,25\% and $40 \%$. Welfare gains are computed for a debt level of $75 \%$ of income.

higher repayment share in default, as shown in Table 5. The benefit of the CDS comes from lower spreads in case of repayment. The disadvantage of the CDS is that the country will have to repay more in default, which is usually a state with low output. As one can observe in Figure 5, for low levels of CDS, the benefit outweights the cost, so the existance of the CDS is welfare improving. For high levels of CDS and low income shock, the disadvantage is higher than the benefit, since there is a higher probability of default.

Following Chatterjee and Eyigungor (2013), I can use a similar criterion to compare welfare between steady states. They measure welfare as the value of constant consumption that gives the same average lifetime utility starting from zero debt and zero transitory income shock (the average is computed over the invariant distribution of $y$ ). The results are presented on Table 6, as a percent increase from the welfare with no CDS. Overall, CDS increases the welfare of the country, because it acts as a credible commitment device. The country will not default in states that it would in the absence of CDS. This leads to lower default probabilities, for any combination of states (debt and income). This higher commitment allows the country to borrow more, as is the case with $40 \%$ CDS covered debt. Higher debt levels can decrease welfare because the country ends up defaulting more often (equilibrium probability of default is $3.11 \%$ with $40 \%$ CDS). Also, with CDS the country has to repay more in default states which coincide with periods of low income, reducing welfare. 
Table 6: CDS Welfare Effects

\begin{tabular}{ccc}
\hline $5 \% C D S$ & $25 \% C D S$ & $40 \% C D S$ \\
\hline 0.05 & 0.06 & -0.03
\end{tabular}

Note: The table shows $\left[\left(\right.\right.$ welfare $_{C D S} /$ welfare $\left.\left._{N O} C D S\right)-1\right] \times 100$

\section{Conclusion}

This paper proposes a dynamic endogenous default model with post-default bargaining and long-term CDS contracts. It shows that the existence of a CDS contract increases the lenders' bargaining power during debt renegotiation, increasing the share repaid by the country in renegotiation for all debt levels. With a CDS market, the borrower must compensate lenders for lower expected insurance payments upon accepting the agreement regarding the debt renegotiation. The country compensates its lenders by increasing the debt share repaid. Because the country has to pay more in default, this option becomes less attractive. Therefore, the country can credibly commit to not defaulting in more states of the world. This leads to higher equilibrium debt levels and lower debt financing cost. Also, the uncertainty over the insurance payout when the bond defaults explains the price discrepancy between CDS and bond.

The model is calibrated to Greek data and uses the pricing dynamics of the CDS and bond during the crisis to infer the market perception of the probability of the insurance paying out when the debt holders incur losses. That is, the market expectation over the Decision Committee function of determining if the renegotiation triggers the CDS. Using this triggering function and assuming that $5 \%$ of the outstanding debt is insured, the model quantitatively matches the behavior of the basis during the crisis. Simulation results indicate that at the current CDS-to-debt ratios of $5-10 \%$, the unconditional probability of default and the spread are both lower than in a "no CDS" benchmark. The calibration for Greece reveals that increasing the CDS-to-debt ratio from 0 to $5 \%$ lowers the unconditional probability of default from $2.6 \%$ to $2.0 \%$ per year, with negligible effects on the average debt-to-GDP ratio. If the level of insured debt is increased to $40 \%$, the equilibrium debt-to-GDP ratio increases by $15 \%$ and the probability of default increases to $3.11 \%$.

The CDS at current levels (5-10\%) is welfare-improving because it allows countries to smooth consumption better by paying lower spreads. The lender and insurer's welfare levels are unchanged, so the introduction of the CDS at those levels is a Pareto improvement. On the other hand, if the CDS level is too high (40\%) and output low, the welfare of the country decreases. This is because the lenders are exceedingly tough in renegotiation and the country must repay a large amount when defaulting, which coincides with states when output is low. 


\section{References}

Aguiar, M. and G. Gopinath (2006). Defaultable debt, interest rates and the current account. Journal of International Economics 69, 64-83.

Aguiar, M. and G. Gopinath (2007). Emerging market business cycles: The cycle is the trend. Journal of Political Economy 115(1), pp. 69-102.

Arce, O., S. Mayordomo, and J. I. Pena (2013). Credit-risk valuation in the sovereign cds and bonds markets: Evidence from the euro area crisis. Journal of International Money and Finance 35(C), 124-145.

Arellano, C. (2008). Default risk and income fluctuations in emerging economies. American Economic Review 98(3), 690-712.

Arellano, C. and A. Ramanarayanan (2012). Default and the maturity structure in sovereign bonds. Journal of Political Economy 120(2), 187 - 232.

Arora, N., P. Gandhi, and F. A. Longstaff (2012). Counterparty credit risk and the credit default swap market. Journal of Financial Economics 103(2), 280 - 293.

Augustin, P., M. G. Subrahmanyam, D. Y. Tang, and S. Q. Wang (2014). Credit default swaps-a survey. Foundations and Trends in Finance, forthcoming.

Bai, J. and P. Collin-Dufresne (2013). The cds-bond basis. Manuscript.

Benjamin, D. and M. L. J. Wright (2009). Recovery Before Redemption: A Theory Of Delays In Sovereign Debt Renegotiations.

Blanco, R., S. Brennan, and I. W. Marsh (2005). An empirical analysis of the dynamic relation between investment-grade bonds and credit default swaps. The Journal of Finance $60(5)$, pp. 2255-2281.

Bolton, P. and M. Oehmke (2011). Credit default swaps and the empty creditor problem. Review of Financial Studies 24(8), 2617-2655.

Chatterjee, S. and B. Eyigungor (2012). Maturity, indebtedness, and default risk. American Economic Review 102(6), 2674-99.

Chatterjee, S. and B. Eyigungor (2013). Debt dilution and seniority in a model of defaultable sovereign debt. Working Papers 13-30, Federal Reserve Bank of Philadelphia. 
Cruces, J. J. and C. Trebesch (2013). Sovereign defaults: The price of haircuts. American Economic Journal: Macroeconomics 5(3), 85-117.

Eaton, J. and M. Gersovitz (1981). Debt with potential repudiation: Theoretical and empirical analysis. Review of Economic Studies 48(2), 289-309.

Foley-Fisher, N. (2010). Explaining sovereign bond-cds arbitrage violations during the financial crisis. Manuscript.

Fontana, A. and M. Scheicher (2010). An analysis of euro area sovereign cds and their relation with government bonds. Technical report.

Giglio, S. (2011). Credit default swap spreads and systemic financial risk. Proceedings 1122, Federal Reserve Bank of Chicago.

Hatchondo, J. C. and L. Martinez (2009). Long-duration bonds and sovereign defaults. Journal of International Economics 79(1), 117-125.

Hatchondo, J. C., L. Martinez, and H. Sapriza (2010). Quantitative properties of sovereign default models: solution methods. Review of Economic Dynamics 13(4), 919-933.

Hatchondo, J. C., L. Martinez, and C. Sosa Padilla (2014). Voluntary sovereign debt exchanges. Journal of Monetary Economics 61(C), 32-50.

Hu, H. T. C. and B. S. Black (2007). Hedge funds, insiders, and the decoupling of economic and voting ownership: Empty voting and hidden (morphable) ownership. Journal of Corporate Finance.

Hull, J., M. Predescu, A. White, J. L. Rotman, J. Fons, L. Gagnon, J. Hyman, H. Hao, L. Johnson, and C. Mann (2004). The relationship between credit default swap spreads, bond yields, and credit rating announcements. Journal of Banking and Finance 28, 27892811.

Longstaff, F. A., S. Mithal, and E. Neis (2005). Corporate yield spreads: Default risk or liquidity? new evidence from the credit default swap market. The Journal of Finance 60(5), 2213-2253.

Mayordomo, S., J. I. P. S. de Rivera, and E. S. Schwartz (2010). Are all credit default swap databases equal? Business economics working papers, Universidad Carlos III.

Neumeyer, P. A. and F. Perri (2005). Business cycles in emerging economies: the role of interest rates. Journal of Monetary Economics 52(2), 345-380. 
Oehmke, M. and A. Zawadowski (2013). The anatomy of the cds market. Manuscript.

Reinhart, C. M. and K. S. Rogoff (2010). This Time Is Different: Eight Centuries of Financial Folly, Volume 1 of Economics Books. Princeton University Press.

Rose, A. K. (2005). One reason countries pay their debts: renegotiation and international trade. Journal of Development Economics 77(1), 189-206.

Sambalaibat, B. (2014). Essays in financial economics: Currency risk and pricing kernal volatility, cds and sovereign bond market liquidity, cds as sovereign debt collateral.

Subrahmanyam, M. G., D. Y. Tang, and S. Q. Wang (2012). Does the tail wag the dog? the effect of credit default swaps on credit risk. Working papers, Hong Kong Institute for Monetary Research.

Tauchen, G. and R. Hussey (1991). Quadrature-based methods for obtaining approximate solutions to nonlinear asset pricing models. Econometrica 59(2), pp. 371-396.

Trebesch, C. and J. Zettelmeyer (2012). Deciphering the ecb securities market programme: The case of greek bonds. Manuscript.

Yue, V. Z. (2010). Sovereign default and debt renegotiation. Journal of International Economics $80(2), 176-187$.

Zettelmeyer, J. and F. Sturzenegger (2005). Haircuts; Estimating Investor Losses in Sovereign Debt Restructurings, 1998-2005. Technical report.

Zettelmeyer, J., C. Trebesch, and M. Gulati (2013). The greek debt restructuring: An autopsy. 


\section{Appendix A}

Figure 1A: GDP and CDS-Bond Basis
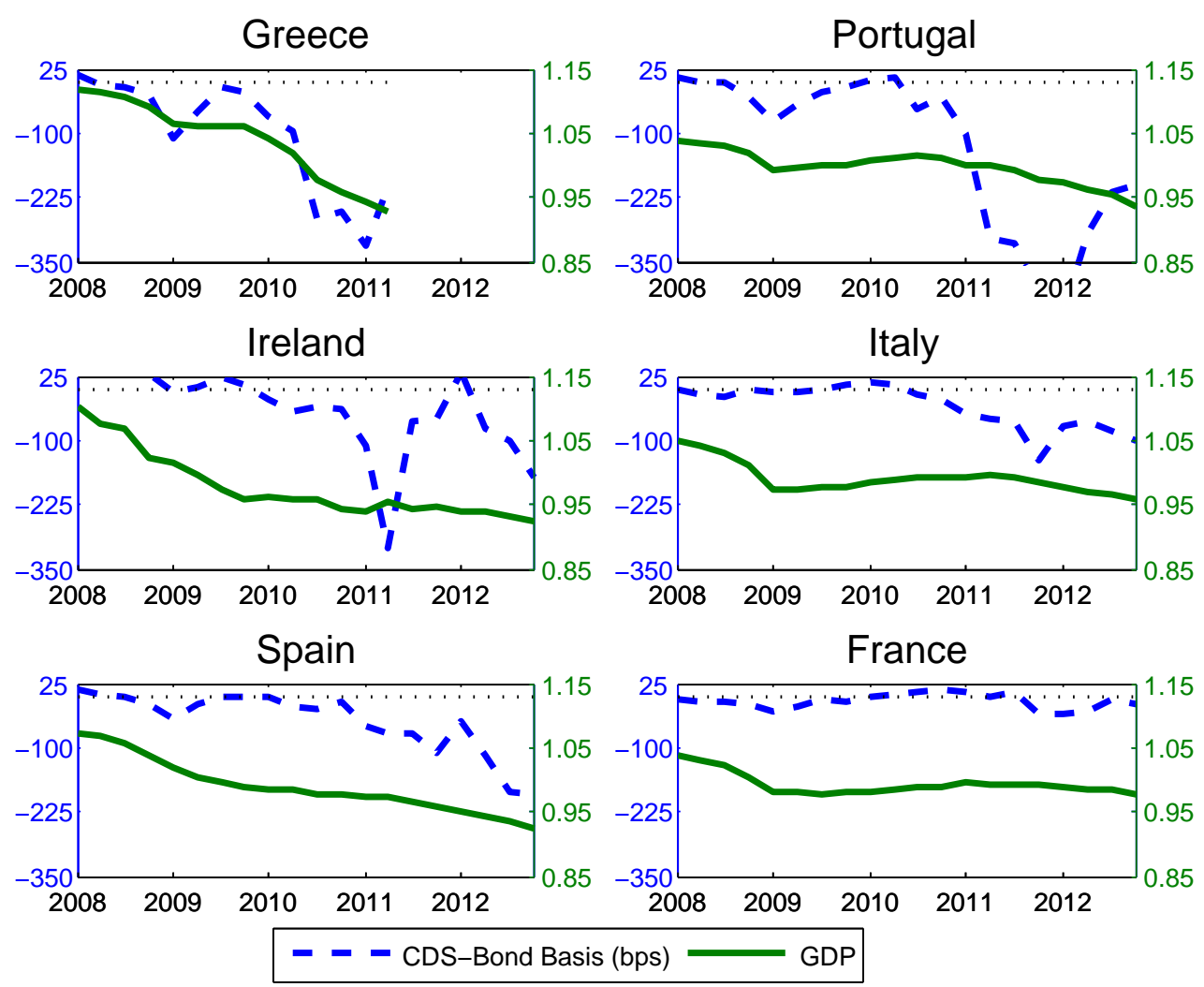

Note: This plot uses seasonally-adjusted and log-detrended RGPD from OECD data. The basis is calculated with 5-year bond and CDS data from Datastream. For Greece, Spain, Ireland, Portugal, and Italy, as GDP goes below the mean (1.0), the basis becomes negative. Low output shocks are usually an indicator of a debt-crisis. In contrast, France also had a small GDP contraction but given it did not have a debt sustainability crisis during this period the basis remains close to zero. 
Figure 2A: CDS-Debt Levels
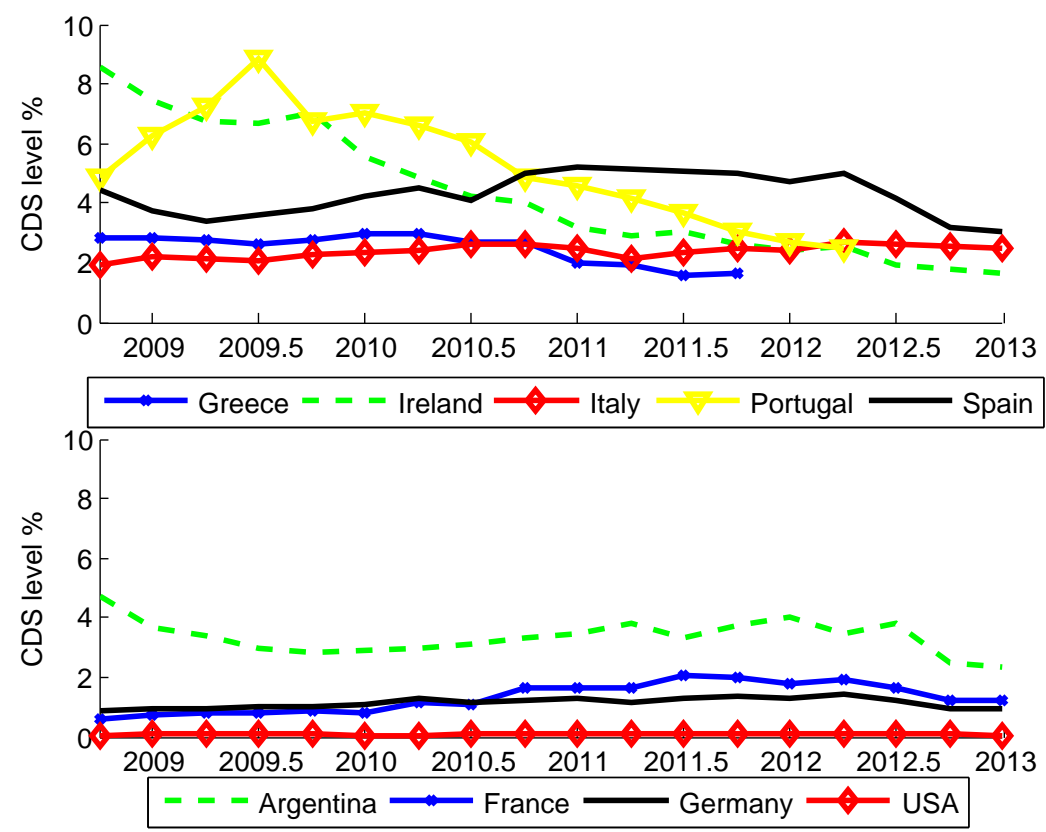

Sources: CDS contracts from DTCC. (does not include CDS Index contract participation). Debt data based on long-term external debt from IMF.

\section{Figure 3A: Timeline Post Default}

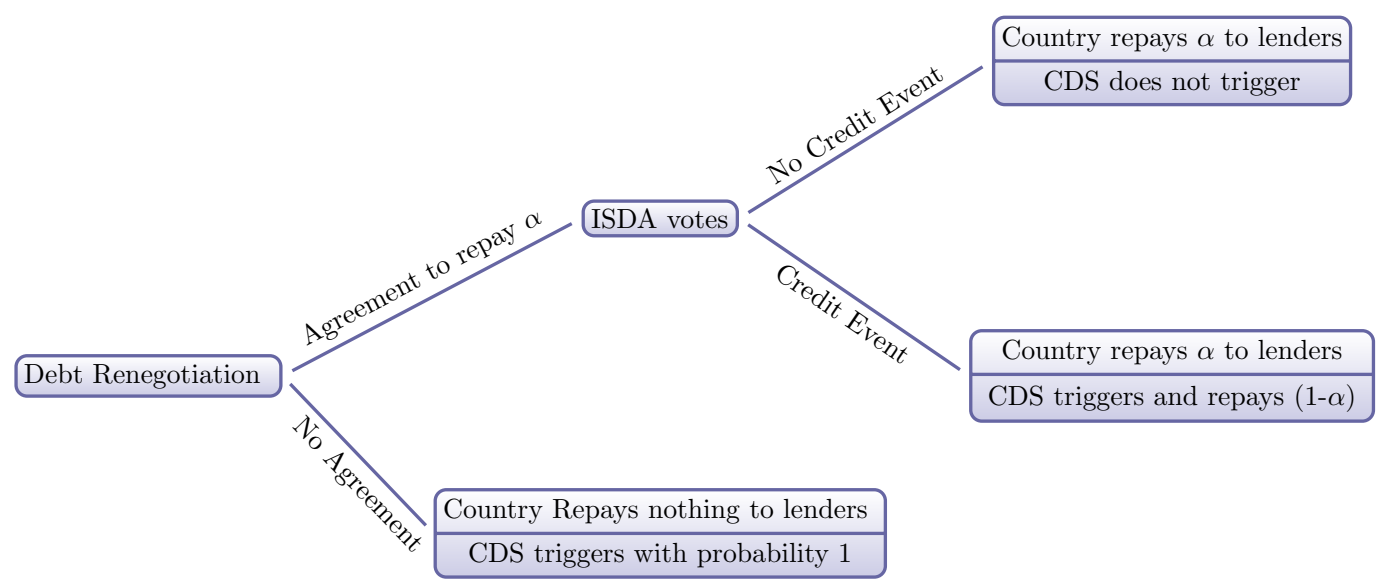




\section{Appendix B}

To illustrate the sensitivity to $\kappa$, the model is solved with probability of triggering parameter $\kappa$ equal to 5 and 0.1 . The results for the simulation with same shock sequence as the one in Table 5 are presented in this appendix.

The average repayment is calculated as the average equilibrium repayment at each debt level and output combination the country chooses in the simulation. If the probability that the CDS will trigger is close to one in most lower levels of repayment (as is the case for $\kappa=5)$ there is very little effect from the CDS on the average repayment and repayment in default for levels of CDS of $5 \%$ and $25 \%$. This is because, with such a high probability of the insurance paying out, the lenders are not as tough, specially if the level of insurance is low.

However, once the level of insurance increases to $40 \%$ of the debt, there is much to lose even at a high probability of triggering. Therefore, the CDS starts to have an effect on repayment levels, which makes default less attractive. This leads to a $10 \%$ lower probability of default (from $2.58 \%$ to $2.31 \%$ per year), lowering spreads by about the same percentage. At lower spreads, the country can consume more because the price of the debt is higher, this leads to an increase on the average consumption.

The basis predicted by a $\kappa$ of 5 , is displayed in Figure 1B. Since there is a high probability of the CDS triggering in case of default, the model will generate a basis close to zero until GDP gets very low.

\begin{tabular}{lcccc}
\multicolumn{5}{c}{ Table 7: Simulation Results $\kappa=5$} \\
\hline & No $C D S$ & $5 \% C D S$ & $25 \% C D S$ & $40 \% C D S$ \\
\hline Repayment (\%) & 94.5 & 94.5 & 94.5 & 94.6 \\
Repayment in Default (\%) & 46.5 & 46.5 & 46.5 & 46.2 \\
Probability of Default (\%) & 2.58 & 2.57 & 2.57 & 2.31 \\
Debt/GDP (\%) & 74.7 & 74.7 & 74.7 & 74.6 \\
Bond Spread (\%) & 2.03 & 2.02 & 2.02 & 1.81 \\
Avg. Consumption & 0.9917 & 0.9917 & 0.9917 & 0.9921 \\
\hline
\end{tabular}

Note: This table presents simulation results for the probability of triggering parameter $\kappa$ equal to 5. The model is solved with CDS levels of $0 \%, 5 \%, 25 \%$ and $40 \%$. The moments are calculated from 1000 simulations of 1000 observations each. In each simulation, the model is simulated for 5000 periods and the first 4000 observations excluded. 
Figure 1B: Simulation for $\mathrm{CDS}=5 \%$ and $\kappa=5$

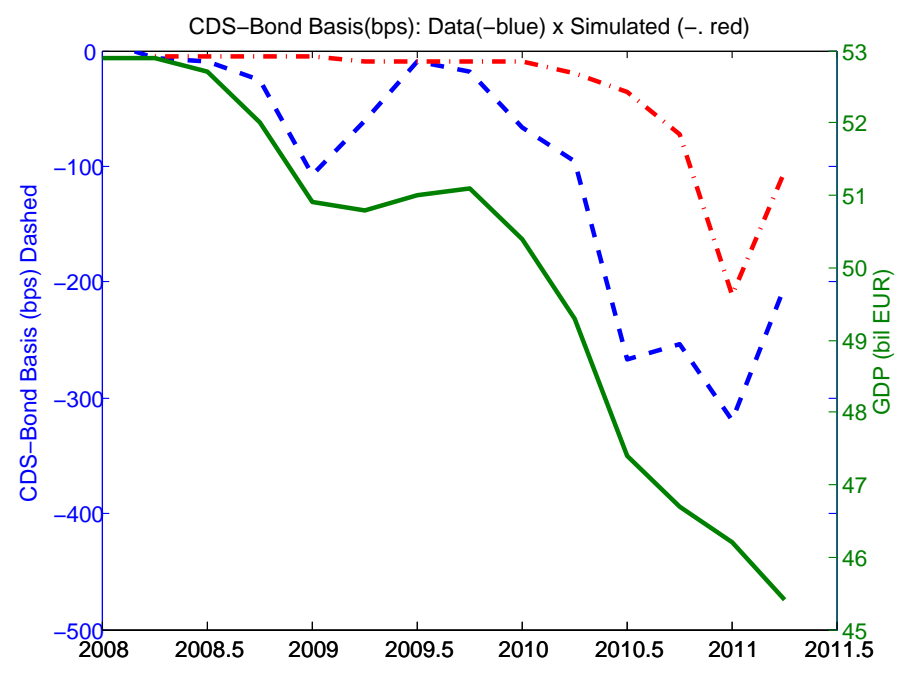

Note: The figure shows simulation results for the basis using the actual Greece output between 2008Q1 and 2011Q2 on the model with 5\% CDS-debt level and $\kappa=5$. The simulated basis is compared to data on the basis on the left axis. The right axis plots the real GDP for Greece in billions of euros. The output data is seasonally adjusted.

Assuming that CDS almost never triggers, unless you get a full default, such as is the case for $\kappa=0.1$. The lenders are going to be extremely tough to bargain with and the CDS is going to have a impact on the repayment share and debt levels.

As one can observe on Table 8, high repayment means committing to not defaulting in a large set of states, lowering the spread for all debt levels. The country chooses to borrow more in equilibrium and ends up defaulting more. This leads to a lower average consumption for CDS levels of $5 \%$ and $25 \%$ when compared to a world without CDS.

The basis predicted by a $\kappa$ of 0.1 , is displayed in Figure $2 \mathrm{~B}$. Since there is a low probability of the CDS triggering in case of default, the model will generate a very negative basis.

In summary, if the level of CDS insured debt is very high, lenders will have a lot to lose if they agree to the renegotiation terms and the insurance does not trigger, so they will be tougher negotiators and the repayment will be higher in equilibrium. If the probability of triggering for a given haircut is very low, there is more uncertainty and the lenders will also be tougher in their negotiation with the country, demanding a higher repayment in default. Also, the basis will be very negative, since the higher the uncertainty, the more imperfect is the insurance and the lower is its price. On the other hand, if uncertainty is very low, that 
is, the CDS triggers with high probability for any haircut, the effect of the CDS in increasing the repayment is small and the basis is not very negative.

Table 8: Simulation Results for $\kappa=0.1$

\begin{tabular}{lccc}
\multicolumn{4}{c}{ Table 8: Simulation Results for $\kappa=0.1$} \\
\hline & No $C D S$ & $5 \% C D S$ & $25 \% C D S$ \\
\hline Repayment (\%) & 94.5 & 95 & 96.5 \\
Repayment in Default (\%) & 46.5 & 47 & 57.2 \\
Probability of Default (\%) & 2.58 & 2.7 & 3.12 \\
Debt/GDP (\%) & 74.7 & 76.5 & 90 \\
Bond Spread (\%) & 2.03 & 2.07 & 2.14 \\
Avg. Consumption & 0.9917 & 0.9913 & 0.9884 \\
\hline
\end{tabular}

Note: This table presents simulation results for the probability of triggering parameter $\kappa$ equal to 0.1. The model is solved with CDS levels of $0 \%, 5 \%$ and $25 \%$. The moments are calculated from 1000 simulations of 1000 observations each. In each simulation, the model is simulated for 5000 periods and the first 4000 observations excluded.

\section{Figure 2B: Simulation for $\mathrm{CDS}=5 \%$ and $\kappa=0.1$}

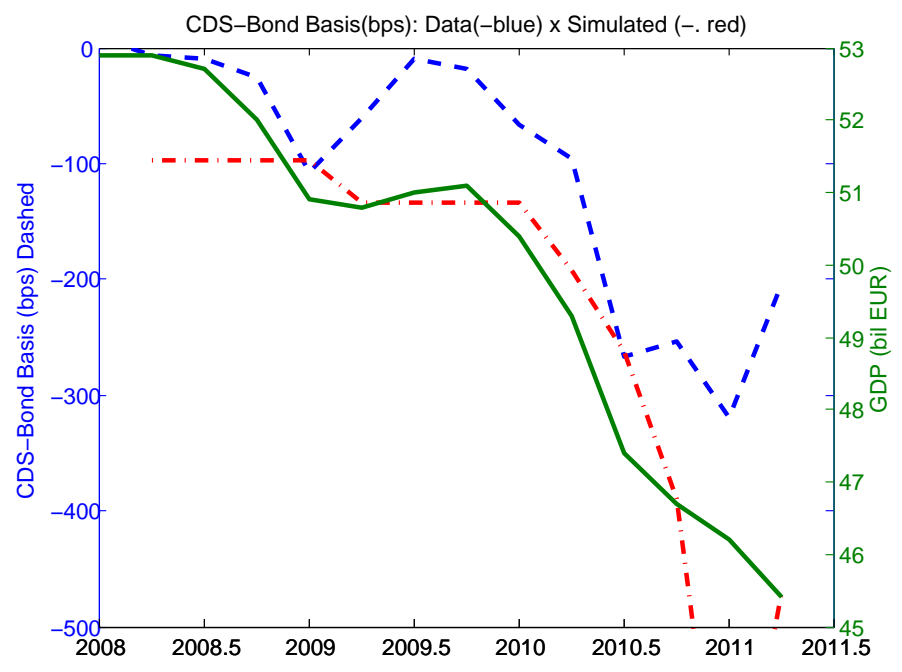

Note: The figure shows simulation results for the basis using the actual Greece output between 2008Q1 and 2011Q2 on the model with 5\% CDS-debt level and $\kappa=0.1$. The simulated basis is compared to data on the basis on the left axis. The right axis plots the real GDP for Greece in billions of euros. The output data is seasonally adjusted. 